ARTICLE OPEN

Check for updates

\title{
3D in vitro M2 macrophage model to mimic modulation of tissue repair
}

\author{
Jiranuwat Sapudom (iD), Shaza Karaman ${ }^{1,2}$, Walaa K. E. Mohamed ${ }^{1}$, Anna Garcia-Sabaté (iD), Brian C. Quartey (D) and \\ Jeremy C. M. Teo iD ${ }^{1,3 凶}$
}

Distinct anti-inflammatory macrophage (M2) subtypes, namely $M 2 a$ and $M 2 c$, are reported to modulate the tissue repair process tightly and chronologically by modulating fibroblast differentiation state and functions. To establish a well-defined threedimensional (3D) cell culture model to mimic the tissue repair process, we utilized THP-1 human monocytic cells and a 3D collagen matrix as a biomimetic tissue model. THP-1 cells were differentiated into macrophages, and activated using IL-4/IL-13 (M $\mathrm{LL}-4 / \mathrm{LL}-13$ ) and IL-10 $\left(\mathrm{M}_{\mathrm{IL}-10}\right)$. Both activated macrophages were characterized by both their cell surface marker expression and cytokine secretion profile. Our cell characterization suggested that $\mathrm{M}_{\mathrm{IL}-4 / \mathrm{LL}-13}$ and $\mathrm{M}_{\mathrm{LL}-10}$ demonstrate M2a- and M2c-like subtypes, respectively. To mimic the initial and resolution phases during the tissue repair, both activated macrophages were co-cultured with fibroblasts and myofibroblasts. We showed that $\mathrm{M}_{\mathrm{IL}-4 / \mathrm{L}-13}$ were able to promote matrix synthesis and remodeling by induction of myofibroblast differentiation via transforming growth factor beta- 1 (TGF- $\beta 1$ ). On the contrary, $\mathrm{M}_{\mathrm{IL}-10}$ demonstrated the ability to resolve the tissue repair process by dedifferentiation of myofibroblast via IL-10 secretion. Overall, our study demonstrated the importance and the exact roles of $\mathrm{M} 2 \mathrm{a}$ and $\mathrm{M} 2 \mathrm{c}$-like macrophage subtypes in coordinating tissue repair in a biomimetic model. The established model can be applied for high-throughput platforms for improving tissue healing and anti-fibrotic drugs testing, as well as other biomedical studies.

npj Regenerative Medicine (2021)6:83; https://doi.org/10.1038/s41536-021-00193-5

\section{INTRODUCTION}

Wound healing is a complex and dynamic process facilitated by four overlapping, continuous phases namely homeostasis, inflammation, proliferation, and tissue remodeling ${ }^{1,2}$. This entire process is tightly modulated and orchestrated by biochemical signals, such as growth factors and cytokines, and biophysical stimuli including cell-cell interactions and cell-extracellular matrix (ECM) interactions ${ }^{3}$. Various cell types, including immune cells, fibroblasts, endothelial cells, and keratinocytes are intricately involved in the wound-healing process ${ }^{4,5}$. In the early phase of wound repair, fibroblasts proliferate and migrate from adjacent tissues towards the wound bed via chemotaxis, in order to form granulation tissue and synthesize new ECM ${ }^{6}$. Fibronectin is a high-molecular weight adhesive glycoprotein that originates from blood plasma and becomes part of the wound matrix due to the rupture of localized vasculature during tissue injury. Fibronectin has also been reported to enhance migration of fibroblasts into wound tissue and stimulate their proliferation ${ }^{7,8}$. Afterwards, fibroblasts differentiate into myofibroblasts via transforming growth factor beta-1 (TGF- $\beta 1$ )-mediated Smad2/3 signaling ${ }^{9,10}$. Recent reports suggest that attenuation of TGF- $\beta 1$ signaling through the use of glycosaminoglycan-based hydrogel reduce scar formation in rat dermal wounds ${ }^{11,12}$, while excessive reduction of TGF- $\beta 1$ can be paradoxical, delaying wound repair $^{13}$. Myofibroblasts are characterized by pronounced actin stress fibers and the expression of alpha smooth-muscle actin (aSMA), as well as an extensive production and deposition of ECM proteins, e.g. type I collagen (Coll I) and fibronectin containing extra domain-A (EDA-FN) ${ }^{8,14,15}$. In addition, they are able to reorganize collagen fibrils of the ECM using their contractile machinery, actively playing a role in physically closing the wound ${ }^{16,17}$. Alongside with that, collagen fibril density is increased during the tissue repair process and, in turn, can act as a negative feedback to downregulate myofibroblastic activity ${ }^{18,19}$. However, if the tissue repair is prolonged and myofibroblasts remain to produce excessive ECM components and steady remodel the tissue, it will result in scarring or fibrosis ${ }^{20,21}$.

Macrophages are known as the most dominating cells at the wound site which coordinate the transition between phases during the entire wound-healing process ${ }^{22-24}$. In particular, antiinflammatory macrophages, known as M2 macrophages, are key regulators in the initiation and resolution of tissue repair phase by secreting specific cytokines to modulate fibroblast fates ${ }^{25,26}$. In classical macrophage biology, M2 macrophages are classified into distinct subtypes, namely $M 2 a, M 2 b, M 2 c, M 2 d$, and M2f based on their marker expressions and cytokine secretion profiles ${ }^{27}$. Macrophage phenotype is in fact a continuous spectrum; however, description through their distinct subtypes provides clarity $^{28}$. It has been hypothesized that the balance between regenerative wound healing and scarring/fibrosis pivots on the equilibrium between the $\mathrm{M} 2 \mathrm{a}$ and $\mathrm{M} 2 \mathrm{c}$ phenotype, each with distinct cellular functions. However, few studies have investigated the role of $\mathrm{M} 2 \mathrm{a}$ and $\mathrm{M} 2 \mathrm{C}$ in other physiological contexts ${ }^{29-31}$ and even less is known about how both cell subtypes regulate fibroblast differentiation and functions.

The limitation of the current in vitro wound-healing model is that most of the previous models were conducted on twodimensional (2D) tissue culture plastic, which lacked representative ECM components and exhibited non-physiological features, such as high mechanical stiffness and lack of porosity ${ }^{32-34}$. To

\footnotetext{
${ }^{1}$ Laboratory for Immuno Bioengineering Research and Applications, Division of Engineering, New York University Abu Dhabi, Abu Dhabi, UAE. ${ }^{2}$ Department of Biomedical Engineering, Imperial College London, London, UK. ${ }^{3}$ Department of Mechanical and Biomedical Engineering, Tandon School of Engineering, New York University, New York, NY,

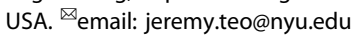


a macrophage differentiation and activation

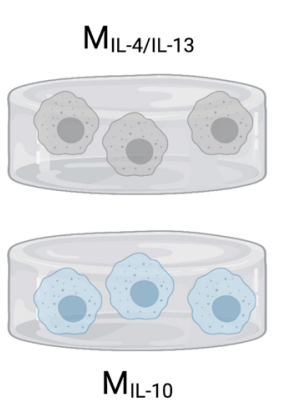

b

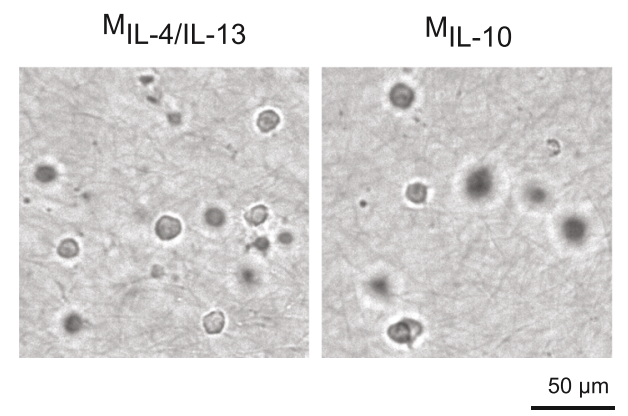

C

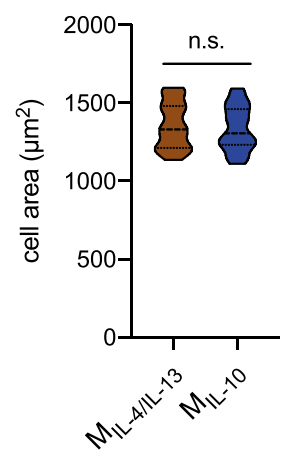

d

cell aspect ratio

Fig. 1 Macrophage differentiation and activation in 3D collagen matrices. a Schematic workflow for macrophage differentiation and activation towards $\mathrm{M}_{\mathrm{LL}-4 / \mathrm{LL}-13}$ and $\mathrm{M}_{\mathrm{LL}-10}$ in 3D collagen matrix. b Representative images of $\mathrm{M}_{\mathrm{IL}-4 / \mathrm{L}-13}$ and $\mathrm{M}_{\mathrm{LL}-10}$ were gathered using bright-field microscopy. A quantitative morphological analysis, namely $\mathbf{c}$ cell area and $\mathbf{d}$ cell aspect ratio, was conducted using an image analysis toolbox. Data are presented as a violin plot. At least 100 cells from three independent experiments were analyzed.

bridge the gap between 2D cell culture models and native tissues, three-dimensional (3D) fibrillar collagen matrices can be utilized to mimic wound tissue, since it recapitulates the fibrillar microstructure of native tissues ${ }^{18,35,36}$. In addition, the 3D collagen systems could be fine-tuned in terms of their biophysical properties, e.g., pore size, fibril size and elasticity ${ }^{33}$, as well as model tissue compartments ${ }^{37}$. Besides, they can be post-modified with other ECM proteins such as fibronectin and glycosaminoglycans to enhance the complexity of the biomimetic models ${ }^{33}$.

The aim of this work is to establish THP-1-derived M2 subtypes, namely M2a and M2c, for utilization in a well-defined 3D collagenbased wound-healing model, facilitating the development of highthroughput platforms for models of wound healing. First, phenotypes of both macrophage subtypes were comprehensively characterized in terms of expression of cell surface markers and cytokine secretion profiles. Afterwards, fibroblasts and myofibroblasts were each co-cultured with both M2 subtypes and studied in terms of their differentiation, matrix protein production, matrix remodeling, and migratory behavior.

\section{RESULTS AND DISCUSSION}

\section{Establish 3D in vitro model and macrophage morphology}

Current wound-healing models are based on 2D tissue culture plastic, lacking many biophysical and biochemical features found in native wound tissue. In this work, we aimed to establish a biomimetic 3D cell culture models to replicate modulation of the initiation and resolution phases of the tissue repair. Our cell culture model facilitates the development of well-defined woundhealing models for high-throughput screening in drug development, studying of cell-cell and cell-matrix interactions, as well as other biomedical studies. We utilized 3D collagen matrices as a $3 \mathrm{D}$ cell culture model. Our 3D collagen matrices reconstituted at $2 \mathrm{mg} / \mathrm{ml}$ collagen concentration, exhibit a pore size of
$8.1 \pm 0.8 \mu \mathrm{m}$, a fibril diameter of $652.0 \pm 32.0 \mathrm{~nm}$, and an elastic modulus of $85.5 \pm 7.3 \mathrm{~Pa}$.

As high-throughput studies require large number of cells and to overcome donor-to-donor variation of primary cells, we utilized THP-1-derived macrophages as a cell model. To generate M2 macrophage subtypes, we first differentiated embedded THP-1 cells into uncommitted macrophages using PMA and further activated them using interleukin-4 (IL-4)/IL-13 and IL-10 into $\mathrm{M}_{\mathrm{IL}-4 /}$ $\mathrm{IL}_{-13}$ and $\mathrm{M}_{\mathrm{LL}-10}$, respectively (Fig. 1a). After macrophage activation, we quantified cell morphology by means of measuring cell area (Fig. 1c) and cell aspect ratio (Fig. 1d) using an automated image analysis toolbox ${ }^{38}$. Both $\mathrm{M}_{\mathrm{IL}-4 / \mathrm{LL}-13}$ and $\mathrm{M}_{\mathrm{IL}-10}$ cells exhibited a round morphological appearance, as visualized in Fig. $1 \mathrm{~b}$ and quantified by cell aspect ratio (Fig. 1d), no significant difference could be found between both macrophage subtypes. Macrophages are distributed homogeneously throughout 3D collagen matrices (Supplementary Fig. 1). For further characterization, we comprehensively studied cell surface markers and cytokine secretion profile. Later, both activated macrophages subtypes were co-cultured with fibroblasts and myofibroblasts to demonstrate differential cellular functions. Specifically, we aim to demonstrate the advantage of our 3D cell culture models for indepth study of collagen reorganization during the initiation and resolution phases of the tissue repair.

\section{Establish and characterization of $\mathrm{M}_{\mathrm{IL}-4 / \mathrm{LL}-13}$ and $\mathrm{M}_{\mathrm{IL}-10}$ macrophage}

To distinguish between the macrophage subtypes used in this study, we first characterized both $\mathrm{M}_{\mathrm{IL}-4 / \mathrm{LL}-13}$ and $\mathrm{M}_{\mathrm{IL}-10}$ cells using their surface marker profile. The expression of CD14, CD68, CD80, CD86, CD105, CD163, CD206, and HLA-DR was measured via immunocytostaining using flow cytometry and quantified by geometric mean fluorescence intensity (gMFI) (Fig. 2). Histogram 

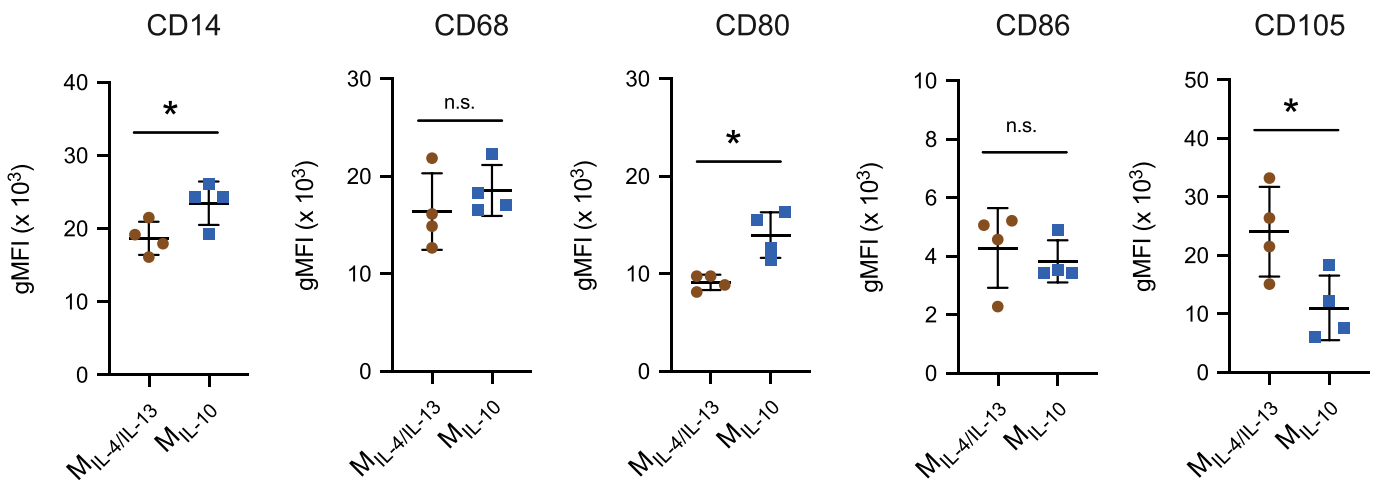

CD163

CD206

HLA-DR
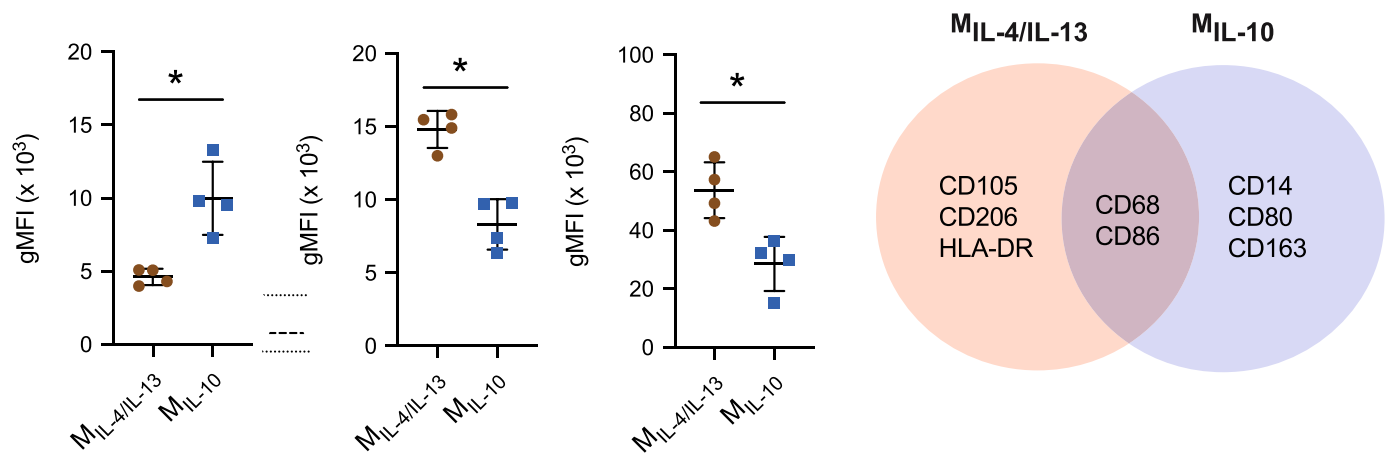

Fig. 2 Quantitative analysis of cell surface markers of $\mathbf{M}_{\mathrm{IL}-4 / \mathrm{LL}-13}$ and $\mathbf{M}_{\mathrm{IL}-10}$. Cell surface markers were analyzed by immunocytostaining of CD14, CD68, CD80, CD86, CD105, CD163, CD206, and HLA-DR. Geometric mean fluorescence intensity (gMFI) was plotted. Black line and error bar in the plot represent mean and standard deviation, respectively. ${ }^{*}$ indicates a significance level of $p \leq 0.05$ using Mann-Whitney test. Experiments were performed in four independent replicates.

plots of quantified surface markers are depicted in Supplementary Fig. 2.

As shown in Fig. 2, both $\mathrm{M} 2$ subtypes shared similar expression levels of CD68 and CD86. Since CD68 is a pan-macrophage marker ${ }^{39}$, it is not surprising that a recent report suggested expression level of CD68 increased upon differentiation in THP-1derived macrophages, as compared to undifferentiated cell ${ }^{40}$. We further showed that THP-1-derived macrophages activated towards pro-inflammatory subtype and treated using IL-4/IL13 showed no difference in CD68 expression ${ }^{40}$. CD86, on the other hand, is reported to be highly expressed in pro-inflammatory macrophages $^{39}$ and hence used to discriminate $\mathrm{M} 2 \mathrm{a}$ and $\mathrm{M} 2 \mathrm{C}$ from pro-inflammatory macrophages ${ }^{41}$.

$\mathrm{M}_{\mathrm{IL}-4 / \mathrm{LL}-13}$ exhibited higher expression levels of CD105, CD206, and HLA-DR when compared to $\mathrm{M}_{\mathrm{IL}-10}$. HLA-DR is generally expressed approximately 5 - to 10 -fold higher in pro-inflammatory macrophages when compared to anti-inflammatory macrophages for both PBMC- and THP-1-derived macrophages ${ }^{27,42}$. In this work, we found a higher expression of HLA-DR in $M_{\mathrm{IL}-4 / \mathrm{LL}-13}$ when compared to $\mathrm{M}_{\mathrm{LL}-10}$ macrophages, suggesting a higher proinflammatory activity of $M_{\mathrm{IL}-4 / \mathrm{LL}-13}$. As for the expression of CD105 and CD206, it is reported that both these surface markers can be induced by IL-4/IL-13 in both PBMC- and THP-1-derived macrophages ${ }^{24,25}$, explaining the high expression of CD105 and CD206 measured in our $\mathrm{M}_{\mathrm{IL}-4 / \mathrm{LL}-13}$. We previously showed that THP1-derived pro-inflammatory macrophages and treated with IL-4/IL13 showed similar levels of CD206.

$\mathrm{M}_{\mathrm{IL}-10}$ expressed high CD14, CD80, and CD163. CD14 is known used as an M2c-specific marker ${ }^{31}$. It has been showed that IL-10 enhanced CD14 expression ${ }^{43}$. In general, CD80 surface markers have been reported to be highly expressed in pro-inflammatory macrophages ${ }^{44,45}$. However, a recent report demonstrated that the presence of CD80 in anti-inflammatory macrophages is involved in the differentiation of regulatory $T$ cells which play an important role in anti-rejection of transplants and maintaining tolerance ${ }^{46,47}$. CD163 is identified as an anti-inflammatory receptor, which expression can be induced by IL-10 (ref. ${ }^{48}$ ). The high expression of CD14, CD80, and CD163 suggest an advanced suppressive role of pro-inflammatory response ${ }^{49,50}$.

To further characterize both M2 phenotypes, we studied the cytokine secretion profile using a multiplex bead-based immunoassay (Fig. 3). To ensure that IL-4, IL-10, and IL-13 were autologously secreted, and not absorbed and released by the collagen through our exogenous application during macrophage activation, collagen matrices were incubated with those cytokines and the release profile in the media was determined over 3 days. Additionally, matrices were digested using collagenase and cytokine levels were quantified. Both soluble or matrixbound IL-4, IL-10, and IL-13 were undetectable using the beadbased immunoassay, and therefore quantified cytokines were secreted by cells.

As shown in Fig. 3, we found significantly higher secretion levels of interferon- $\gamma$ (IFN- $\gamma$ ), IL-2, IL-4, IL-8, IL-12p70, MCP-1, and TGF- $\beta 1$ in $\mathrm{M}_{\mathrm{LL}-4 / \mathrm{LL}-13}$ when compared to $\mathrm{M}_{\mathrm{IL}-10}$. Both cells secreted similar levels of IL-1 $\beta$, IL-6, tumor necrosis factor-a (TNF-a), and IP-10. In general, IFN- $\gamma$, IL-1 $\beta$, IL-6, IL-12p70, IP-10, and TNF-a are proinflammatory cytokines secreted by macrophages during the early wound-healing process ${ }^{51}$; however, they are generally expressed by $\mathrm{M} 1$ macrophages ${ }^{18,40,52}$. Especially, IFN- $\psi, \mathrm{IL}-2, \mathrm{IL}-4$, and IL-12 have been associated with accelerated tissue repair ${ }^{53,54}$ and reported to contribute to effective wound healing. Any dysregulation in the secretion of those cytokines can lead to tissue 
IFN-y

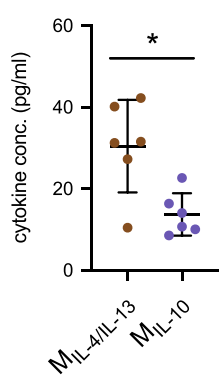

IL-8

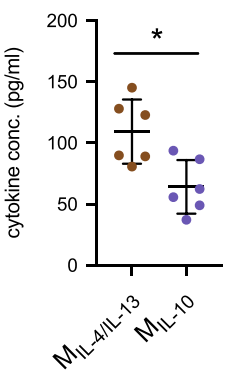

MCP-1

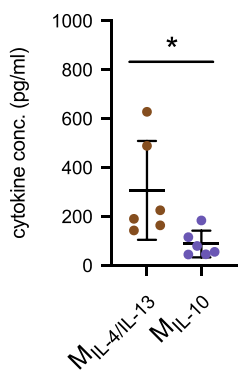

IL-1 $\beta$

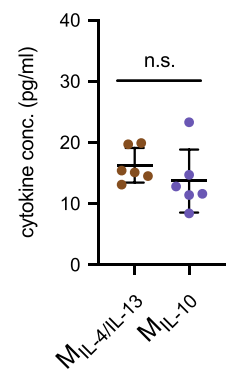

IL-10

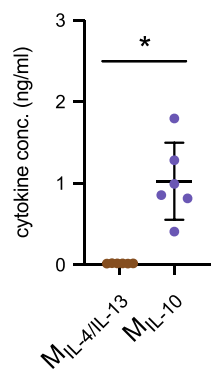

TGF- $\beta 1$

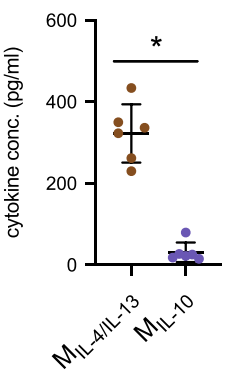

IL-2

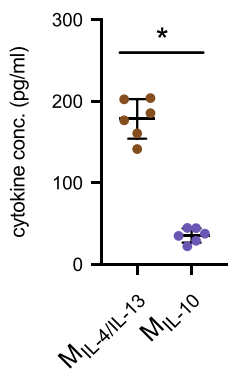

IL-12p70

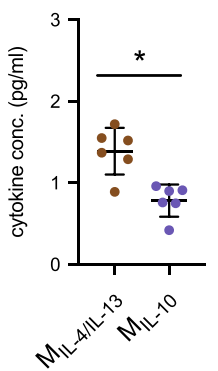

TNF- $\alpha$

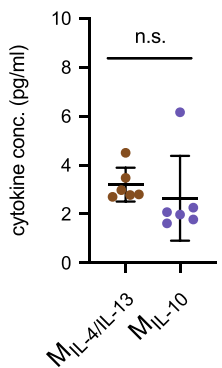

IL-4

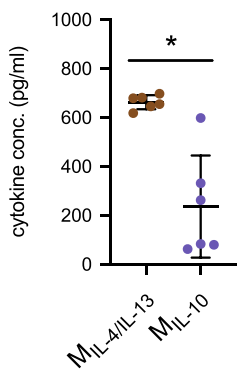

IL-17A
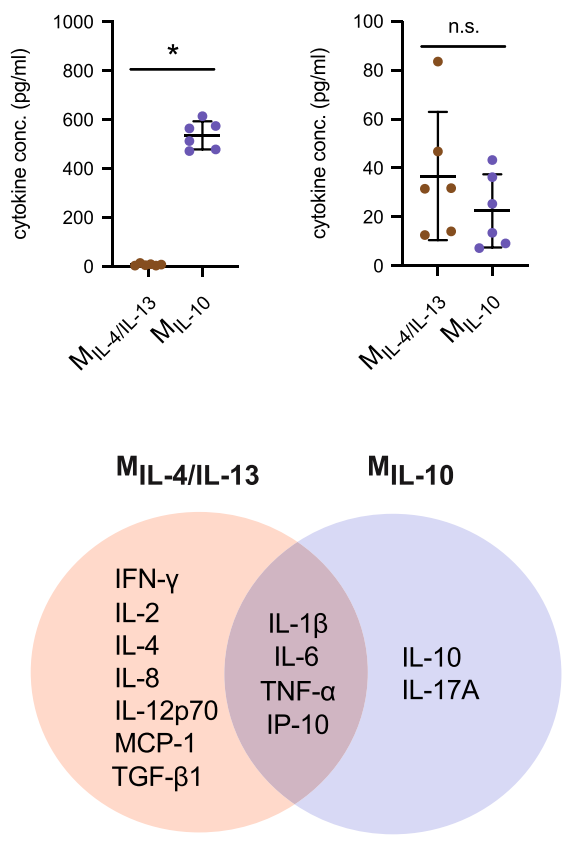

Fig. 3 Quantitative analysis of cytokine secretion profile of $\mathbf{M}_{\mathrm{LL}-4 / \mathrm{IL}-13}$ and $\mathbf{M}_{\mathrm{IL}-10}$. Cytokine secretion profile was analyzed from cell culture supernatants after 3 days of macrophage activation by a bead-based multiplex immunoassay using flow cytometry. Data are shown as a dot plot. Black line and error bar in the plot represent mean and standard deviation, respectively. ${ }^{*}$ indicates a significance level of $p \leq 0.05$ using Mann-Whitney test. Experiments were performed in six independent replicates.

fibrosis $^{55-58}$. In addition to pro-inflammatory cytokines, $\mathrm{M}_{\mathrm{IL}-4 / \mathrm{LL}-13}$ secreted a high amount of TGF- $\beta 1$, a well-known multifunctional cytokine involved in the process of fibroblast differentiation. It has been demonstrated that TGF- $\beta 1$ is secreted by macrophages activated with IL-4/IL-13 in both PBMC and THP-1-derived macrophages ${ }^{18,30}$. The secretion of TGF- $\beta 1$ also supports the maintenance of M2a phenotype ${ }^{59}$.

On the other hand, $\mathrm{M}_{\mathrm{IL}-10}$ produced high amounts of IL-17 and IL-10 which were undetectable from $\mathrm{M}_{\mathrm{IL}-4 / \mathrm{IL}-13}$. While most analyzed pro-inflammatory cytokines have been demonstrated to enhance tissue repair, IL-17 is a pro-inflammatory cytokine that is involved in the activation of $\mathrm{M} 2$ macrophages via NFKB signaling $^{60}$ and the administration of recombinant IL-17A leads to delayed wound healing ${ }^{61}$, which might relate to stimulation of differentiation of human anti-inflammatory macrophages $M 2 c$ in response to IL-10 (ref. ${ }^{62}$ ). IL-10 is the anti-inflammatory cytokine reported to be highly secreted in IL-10 activated PBMC-derived macrophages (M2c) in particular ${ }^{52}$. It is coupled with the regulation of the different phases during wound healing ${ }^{35,63-66}$.
The cytokine secretion profile of our $M_{\mathrm{IL}-4 / \mathrm{LL}-13}$ and $\mathrm{M}_{\mathrm{IL}-10}$ matches that of PBMC-derived $\mathrm{M} 2 \mathrm{a}$ and $\mathrm{M} 2 \mathrm{C}$, respectively ${ }^{52}$. However, it will be incorrect to compare actual levels of secreted cytokines from both PBMC- and THP-1-derived macrophages due to experimental differences in cell number, activation protocols, cell culture dimensionality, biophysical and biochemical properties of cell culture substrate, and cell culture conditions. It should be reiterated that our cytokine analysis is based on activated macrophages in 3D cell culture models. We previously have reported that many cytokines, including IL-1, IL-6, IL-8, IL-10, IL-12, MCP-1, and TGF- $\beta 1$, are secreted in collagen density-dependent manner by macrophages ${ }^{18}$. In that latter study, pro-inflammatory cytokines, IL-1 $\beta$, IL-6, IL-8, and TNFa, were elevated in macrophages treated with LPS/IFN $\gamma$, namely pro-inflammatory macrophages as compared to $\mathrm{M}_{\mathrm{IL}-4 / \mathrm{LL}-13}$.

In sum, surface markers and cytokine secretion profiles suggest that $\mathrm{M}_{\mathrm{IL}-4 / \mathrm{LL}-13}$ and $\mathrm{M}_{\mathrm{IL}-10}$ activated macrophages demonstrate distinct M2 phenotypes, which are in line with previous findings on $\mathrm{M} 2 \mathrm{a}$ and $\mathrm{M} 2 \mathrm{C}$ macrophage subtypes in primary human macrophages $22,28,52$, respectively. 
a

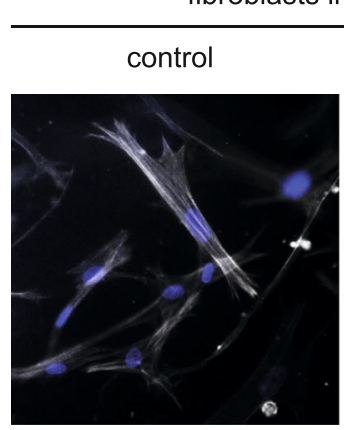

actin aSMA nucleus

aSMA expressed cells

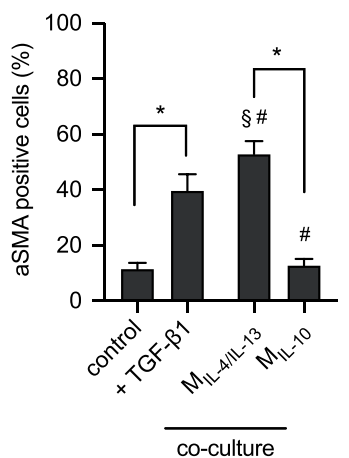

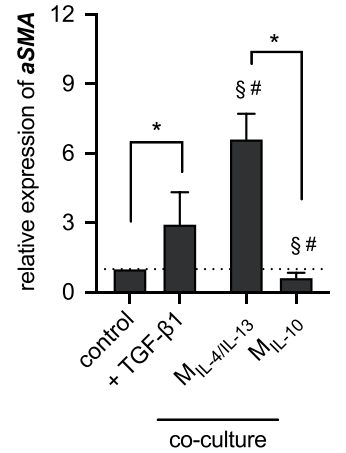

fibroblasts co-cultured with
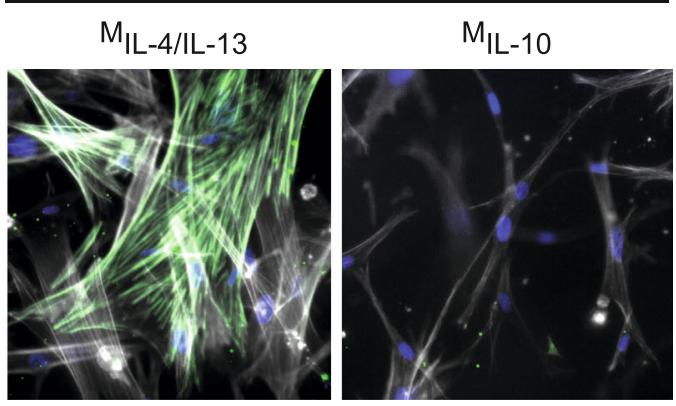

$50 \mu \mathrm{m}$

Coll1a1 expression

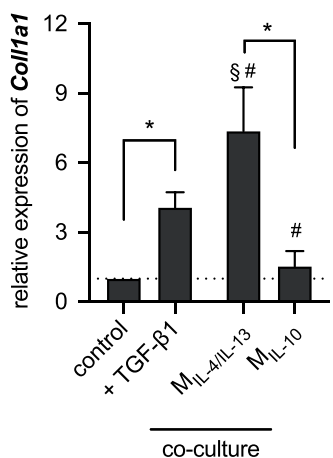

\section{EDA-FN expression}

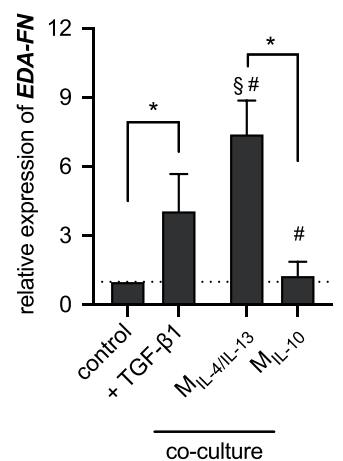

Fig. 4 Alteration of fibroblast morphology and specific markers in the presence of TGF- $\beta 1$ and co-culture with M2 macrophages subtypes. a Representative images showing nuclei (blue), actin filaments (gray), and $\alpha$ SMA (green) (scale bar: $50 \mu \mathrm{m}$ ). Fibroblast differentiation was analyzed by $\mathbf{b}$ manual counting of $\alpha$ SMA-positive cells. At least 200 cells per condition were counted. Gene expression analysis of $\mathbf{c}$ aSMA, d Coll1a1, and e EDA-FN were performed using qPCR. Data are represented as mean \pm SD; *a significance level of $p \leq 0.05$ using a one-way ANOVA followed by Tukey's post hoc analysis. The characters \# and $\S$ represent the significance level of $p \leq 0.05$ using a one-way ANOVA followed by Tukey's post hoc analysis when compared to control, and treated samples with TGF- $\beta 1$, respectively. Experiments were performed in four replicates.

\section{Mimicking the early phase of tissue repair}

To further differentiate between both M2 phenotypes and demonstrate their potential in regulating fibroblast differentiation during the early phase of tissue repair, human primary dermal fibroblasts were co-cultured with M2 phenotypes for 3 days and myofibroblast-related genes were analyzed using qPCR analysis (Fig. 4). Respectively, as negative and positive control of myofibroblast differentiation, fibroblasts were monocultured in the absence and presence of $10 \mathrm{ng} / \mathrm{ml} \mathrm{TGF-} \beta 1$ for 3 days. TGF- $\beta 1$ is known to trigger fibroblast differentiation in vitro ${ }^{21,67}$. Fibroblasts cultured in the presence of TGF- $\beta 1$ and co-cultured with our $\mathrm{M}_{\mathrm{LL}-4 / \mathrm{LL}-13}$ exhibited more pronounced actin stress fibers with aSMA incorporation as well as a more flattened cell morphology, suggesting a differentiation of fibroblast into myofibroblast (Fig. 4a). This could not be observed in untreated fibroblasts (control) and those co-cultured with $\mathrm{M}_{\mathrm{IL}-10}$.

To confirm the fibroblast differentiation, we quantified aSMA expression, a myofibroblast marker ${ }^{8,68}$, using immunocytostaining (Fig. 4b) and gene expression (Fig. 4c) analysis. aSMA-positive cells and gene expression increased in fibroblast culture treated with TGF- $\beta 1$ and when co-cultured with $\mathrm{M}_{\mathrm{IL}-4 / \mathrm{LL}-13 \text {, when compared to }}$ control and co-cultured with $\mathrm{M}_{\mathrm{IL}-10}$. Both aSMA-positive cells and gene expression correlated nicely. This result also corroborates with previous reports which demonstrate the effect of TGF- $\beta 1$ (refs. ${ }^{8,66,69}$ ) and $\mathrm{M}_{\mathrm{IL}-4 / \mathrm{LL}-13}$ mediated fibroblast differentiation ${ }^{18}$. Besides aSMA expression, we analyzed matrix protein production potential, through analyzing alpha 1 chain of the type 1 collagen (Coll1a1) and fibronectin containing Extra Domain-A (EDA-FN). The expression of both Coll1a1 (Fig. 4d) and EDA-FN (Fig. 4e) follow the same trend of aSMA expression. Again, Coll1a1 and EDA-FN were highly expressed in fibroblast co-cultured with $\mathrm{M}_{\mathrm{IL}-4 / \mathrm{LL}-13}$ rather than TGF- $\beta 1$-treated fibroblasts. Fibroblasts co-cultured with $\mathrm{M}_{\mathrm{IL}-10}$ did not show an enhanced expression and the expression level of both matrix proteins was in the same range as untreated fibroblasts.

In sum, by co-culturing fibroblasts with both macrophage subtypes, we found that only $\mathrm{M}_{\mathrm{IL}-4 / \mathrm{LL}-13}$ is able to differentiate fibroblast into myofibroblast, as demonstrated by aSMA and matrix protein expression. This could be explained by the higher TGF- $\beta 1$ expression in $\mathrm{M}_{\mathrm{IL}-4 / \mathrm{LL}-13}$ when compared to $\mathrm{M}_{\mathrm{IL}-10}$ (Fig. 3). Interestingly, the expression levels of aSMA and matrix protein in fibroblast co-cultured with $\mathrm{M}_{\mathrm{IL}-4 / \mathrm{LL}-13}$ are significantly higher than fibroblast directly treated with TGF- $\beta 1$, which is to our previous finding ${ }^{18}$. This variation could be explained by the sustained release of TGF- $\beta 1$ by $\mathrm{M}_{\mathrm{LL}-4 / \mathrm{LL}-13}$. As demonstrated using controlled release microbeads, pulsed paracrine delivery of TGF- $\beta 1$ in a picogram range $(100 \mathrm{pg} / \mathrm{ml})$ from polyethylene glycol (PEG) microbeads embedded in $3 D$ collagen matrix could fully differentiate fibroblasts into myofibroblast similar to a continuous $10 \mathrm{ng} / \mathrm{ml}$ systematic delivery ${ }^{69}$.

Besides production of matrix proteins, another major feature reserved for myofibroblasts is their ability to remodel the matrix. 
a

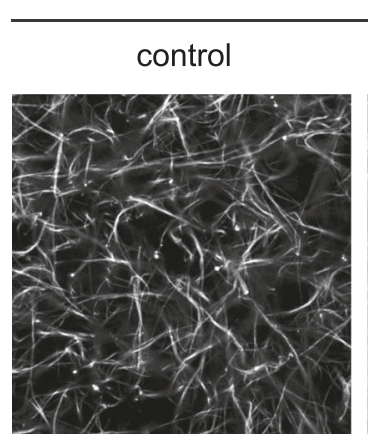

fibroblasts in monoculture

$$
+ \text { TGF- } \beta 1
$$

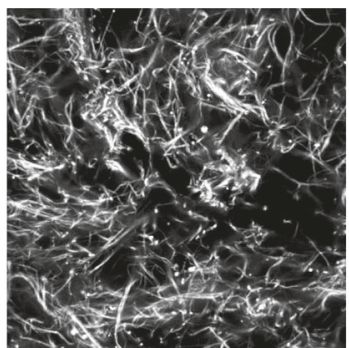

fibroblasts co-cultured with

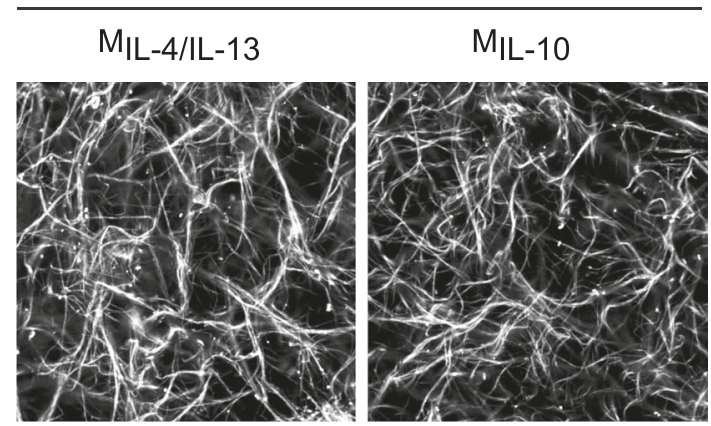

$50 \mu \mathrm{m}$ b

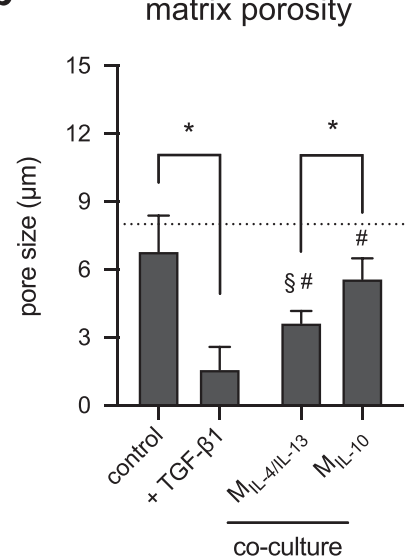

C

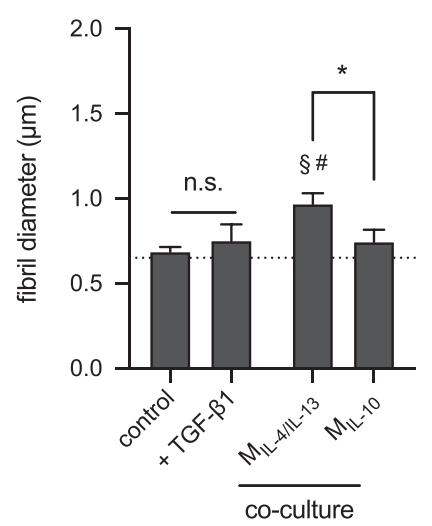

d

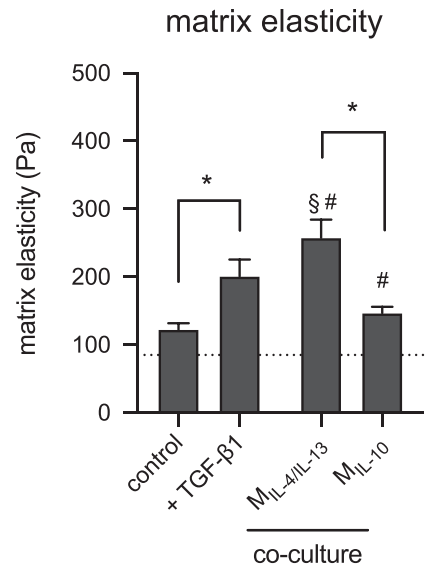

Fig. 5 Matrix remodeling by fibroblasts in the presence of TGF- $\beta 1$ and co-culture with M2 subtypes. a Representative images of decellularized collagen matrices in mono and co-culture with $\mathrm{M} 2$ subtypes (scale bar: $50 \mu \mathrm{m}$ ). Decellularized collagen matrices were characterized regarding $\mathbf{b}$ matrix porosity characterized as mean pore size, $\mathbf{c}$ collagen fibril diameter, and $\mathbf{d}$ bulk matrix elastic modulus (data are represented as mean \pm SD; * significance level of $p \leq 0.05$ using a one-way ANOVA followed by Tukey's post hoc analysis). The characters \# and $\S$ represent the significance level of $p \leq 0.05$ using a one-way ANOVA followed by Tukey's post hoc analysis when compared to control, and treated samples with TGF- $\beta 1$, respectively. For the quantification of matrix porosity and collagen fibril diameter, 10 different positions of each matrix condition were analyzed. Experiments were performed in four replicates.

Collagen matrices were decellularized using osmotic pressure by incubating in bi-distilled water and stained using TAMRA-SE for visualization by confocal laser microscopy (Fig. 5a). Changes in matrix characteristics could be visually observed. The quantitative analysis of matrix porosity and fibril diameter using a custom-built image analysis toolbox demonstrated that matrices of TGF- $\beta 1$ treated fibroblasts exhibit a higher collagen density than the untreated counterpart and matrices of fibroblast co-cultured with both M2 macrophage (Fig. 5b). Matrices of fibroblast co-cultured with $M_{\mathrm{IL}-4 / \mathrm{LL}-13}$ showed significantly smaller pore size than when co-cultured with $\mathrm{M}_{\mathrm{IL}-10}$. Interestingly, an increase in collagen fibril diameter was only found in matrices of fibroblast co-cultured with $\mathrm{M}_{\mathrm{IL}-4 / \mathrm{IL}-13}$. This observation is consistent with the initial development of fibrosis, where an increase of collagen fibril can be found in pro-inflammatory milieu ${ }^{70}$, which at low levels, our $\mathrm{M}_{\mathrm{IL}-4 / \mathrm{LL}-13}$ are able to secrete (Fig. 3). In addition, it has been reported that collagen fibril diameter can mechanically actuate myofibroblast differentiation ${ }^{71}$, which might also explain why fibroblast differentiation in co-culture with $\mathrm{M}_{\mathrm{IL}-4 / \mathrm{LL}-13}$ exhibited higher expression of aSMA (Fig. 4b, c) and matrix proteins (Fig. 4d, e).

Furthermore, we analyzed the elastic modulus of the remodeled matrices using a contactless rheometer (Fig. 5d). Matrices of untreated fibroblast and fibroblast co-culture with $\mathrm{M}_{\mathrm{IL}-10}$ showed a similar range of elastic modulus. Interestingly, matrices of fibroblast co-cultured with $\mathrm{M}_{\mathrm{IL}-4 / \mathrm{IL}-13}$ showed higher elastic modulus than that from TGF- $\beta 1$-treated fibroblasts. As demonstrated in various works ${ }^{71-74}$, the contribution of collagen fibril diameter on bulk matrix modulus is not negligible. For example, collagen matrices with bigger pore size and thicker fibrils demonstrated higher elastic modulus than matrices with smaller pore size and thinner fibrils ${ }^{72,74}$. These previous findings provide an explanation for our obtained results of mechanical analysis.

\section{Mimicking the resolution phase of tissue repair}

While $\mathrm{M}_{\mathrm{IL}-4 / \mathrm{IL}-13}$ has shown their potential in initiating tissue repair, $\mathrm{M}_{\mathrm{IL}-10}$ has been hypothesized to terminate the tissue repair phase due to their low pro-inflammatory cytokine secretion and high secretion of IL-10 (Fig. 3). It has been reported that exogenously applied IL-10 is able to convert myofibroblasts into fibroblast ${ }^{35,66}$. However, few studies have been performed in co-culture conditions to investigate this phenomenon ${ }^{35}$. To address this, we first derived myofibroblasts by treating fibroblasts with $10 \mathrm{ng} /$ $\mathrm{ml}$ TGF- $\beta 1$ on 2D cell culture plastic for 3 days. Afterwards, myofibroblasts were detached and cultured on top of the collagen matrices pre-embedded with and without M2 subtypes. It has to be noted that the cell culture media of the myofibroblast in the control condition is TGF- $\beta 1$ supplemented $(10 \mathrm{ng} / \mathrm{ml})$ to prevent myofibroblast apoptosis, as previously reported ${ }^{66}$. It is known that TGF- $\beta 1$ can block the intrinsic apoptotic pathway by inhibiting the pro-apoptotic protein $\mathrm{BCL}-2$-associated death promoter (BAD) via the FAK-PI3K-AKT signaling pathway in fibroblast ${ }^{75}$. 


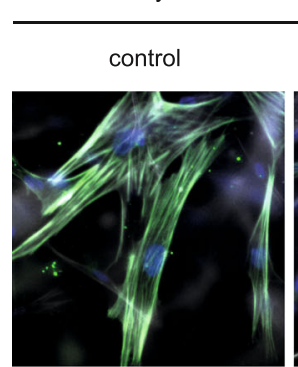

actin aSMA nucleus myofibroblasts co-cultured with
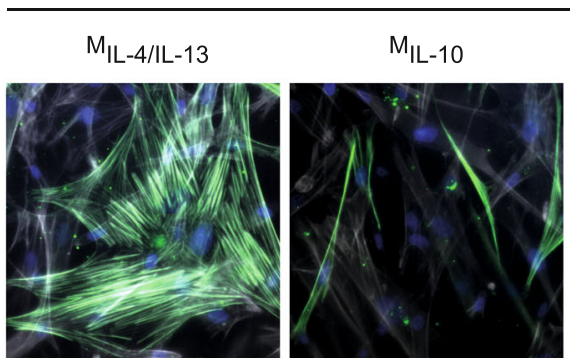

$\mathrm{M}_{\mathrm{IL}-10}+$ alL-10

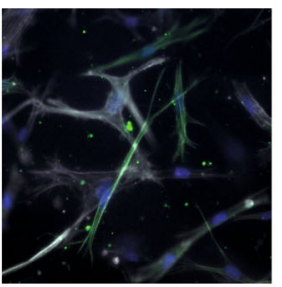

C

aSMA expression

d

Coll1a1 expression

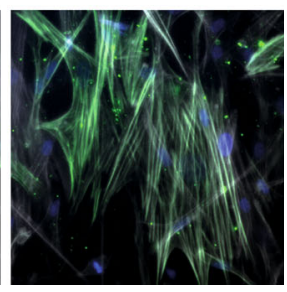

$50 \mu \mathrm{m}$ b

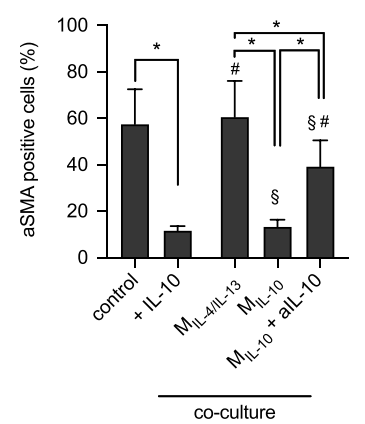

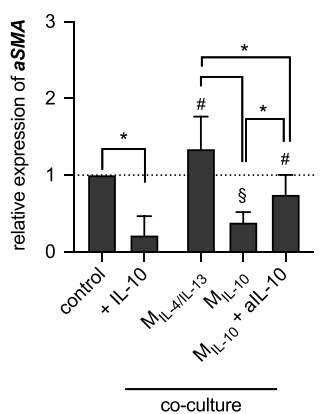
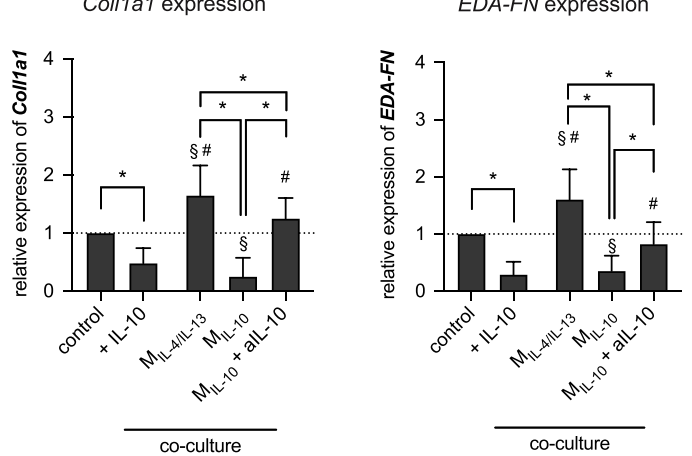

Fig. 6 Alteration of myofibroblasts morphology and specific markers in the presence of IL-10 and co-culture with M2 macrophages subtypes. a Representative images showing nuclei (blue), actin filaments (gray), and $\alpha \mathrm{SMA}$ (green) (scale bar: $50 \mu \mathrm{m})$. Myofibroblast dededifferentiation were analyzed using b percentage of $\alpha S M A$-positive cells by manual counting of cells with $\alpha S M A$ incorporation into actin stress fibers and quantitative analysis of $\mathbf{c}$ aSMA, d Coll1a1, and e EDA-FN gene expression. For quantitative analysis of $\alpha S M A-p o s i t i v e ~ c e l l s$, at least 200 cells per condition were counted. Data are represented as mean \pm SD; *significance level of $p \leq 0.05$ using a one-way ANOVA followed by Tukey's post hoc analysis). The characters \# and § represent the significance level of $p \leq 0.05$ using a one-way ANOVA followed by Tukey's post hoc analysis when compared to control, and treated samples with IL-10, respectively. Experiments were performed in four replicates.

While myofibroblasts in monoculture exhibit pronounced actin stress fibers with aSMA incorporation (Fig. 6a), this observation is attenuated when IL-10 is present systemically. Quantitative analysis of aSMA-positive cells (Fig. 6b) and aSMA expression (Fig. $6 c$ ) confirmed the observation, along with reduction matrix proteins expression, namely Coll1a1 (Fig. 6d) and EDA-FN (Fig. 6e). In co-culture conditions, myofibroblastic phenotypes are maintained in the presence of $\mathrm{M}_{\mathrm{IL}-4 / \mathrm{LL}-13}$, while myofibroblasts co-cultured with $\mathrm{M}_{\mathrm{IL}-10}$ manifests a reduction in aSMA-positive cells and expression. The expression of matrix proteins was also reduced and correlated fittingly with the reduction of aSMA expression. Both results suggested the dedifferentiation of myofibroblast into fibroblast phenotypes when co-cultured with $\mathrm{M}_{\mathrm{IL}-10}$, which is in line with dedifferentiation of myofibroblasts by PBMC-derived anti-inflammatory macrophages using macrophage colony-stimulating factor (M-CSF) ${ }^{35}$. To elucidate that myofibroblast dedifferentiation is related to the secretion of IL-10, we subsequently supplemented cell culture media with anti-IL-10 antibody (alL-10). Results suggested that in the presence of alL-10, the number of aSMA-positive cells and expression, as well as the expression of matrix proteins, remained at a similar level to control and co-culture with $\mathrm{M}_{\mathrm{IL}-4 / \mathrm{LL}-13}$. Our results are in line with the presence of $\mathrm{M} 2 \mathrm{C}$, as well as a detected IL-10 secretion in the late state of the tissue repair phase ${ }^{35,66,76}$, which emphasized the importance of IL-10 in the myofibroblast dedifferentiation process, and hence, termination of the tissue repair phase.

The question arises whether de-differentiated myofibroblasts are able to remodel collagen matrices. To address this underlying question, we decellularized collagen matrices and analyzed their matrix porosity, fibril diameter, and matrix elasticity. Changes in matrix characteristics could be visually observed (Fig. 7a) and further quantitative analysis of matrix porosity showed that matrices of myofibroblasts treated with IL-10 and in co-culture with $\mathrm{M}_{\mathrm{IL}-10}$ were significantly higher than those found in the coculture with $\mathrm{M}_{\mathrm{IL}-4 / \mathrm{IL}-13}$, and $\mathrm{M}_{\mathrm{IL}-10}$ in the presence of alL-10 (Fig. 7b). By analyzing collagen fibril diameter, we found that fibril diameter increased only in co-cultured conditions with $\mathrm{M}_{\mathrm{IL}-4 / \mathrm{LL}-13 \text {, }}$ but not in monoculture and co-culture with $\mathrm{M}_{\mathrm{IL}-4 / \mathrm{LL}-13}$ and $\mathrm{M}_{\mathrm{IL}-10}$ with alL-10 (Fig. 7b). This observation is similar to the one found in co-culture of fibroblast and $\mathrm{M}_{\mathrm{IL}-4 / \mathrm{LL}-13}$ (Fig. 5), which might be caused by the enhanced pro-inflammatory milieu, tissue stiffness, microRNA ${ }^{77,78}$. Significantly lower matrix elasticity could be observed in myofibroblast treated with IL-10 and in co-culture with $\mathrm{M}_{\mathrm{IL}-10}$ (Fig. 7d). Together with aSMA expression and matrix production, our matrix remodeling data suggest the dedifferentiation of myofibroblasts into fibroblast phenotypes in the presence of IL-10 and $\mathrm{M}_{\mathrm{IL}-10}$. By blocking IL-10 using neutralizing antibody (alL-10), we found that the expression of aSMA, matrix proteins, and the matrix remodeling remains at similar levels as myofibroblasts. It suggests that the dedifferentiation of myofibroblast is in response to the presence of supplemented or $\mathrm{M}_{\mathrm{IL}-10}$ secreted IL10. Our data emphasize the importance of IL-10 on the reduction of matrix remodeling by initiation of myofibroblast dedifferentiation.

\section{Fibroblast differentiation state is correlated with migratory behavior}

Besides matrix remodeling, another advantage of the 3D cell culture models is they allow to study cell migration. Migration of fibroblast cells during different stages of wound healing is 
a

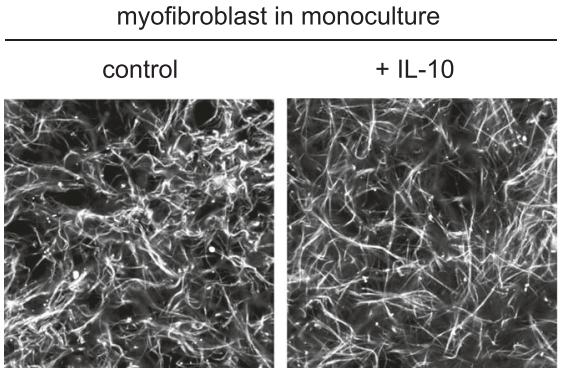

myofibroblast co-cultured with
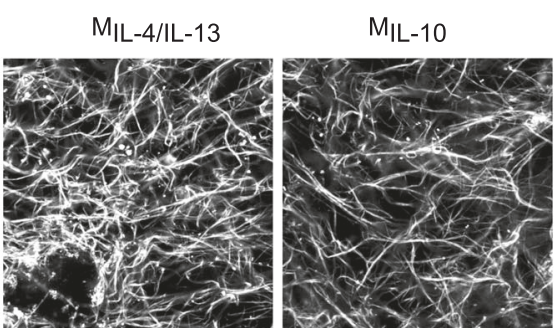

$\mathrm{M}_{\mathrm{IL}-10}+$ alL-10

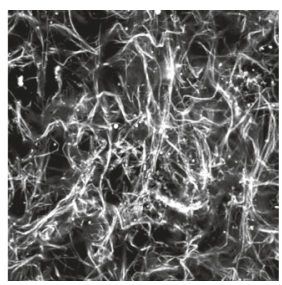

$50 \mu \mathrm{m}$ b

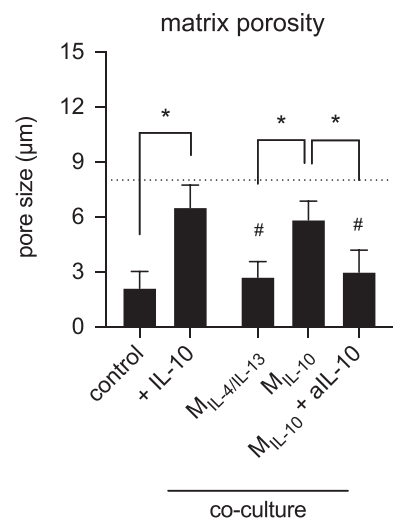

c

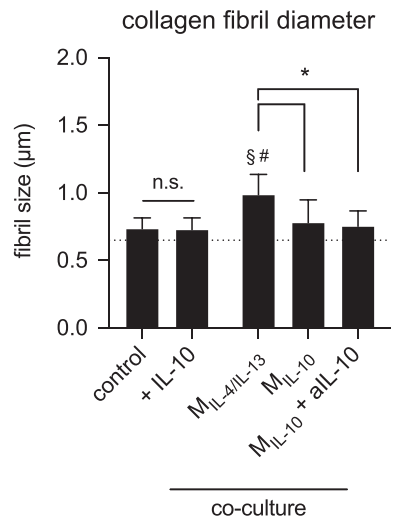

d

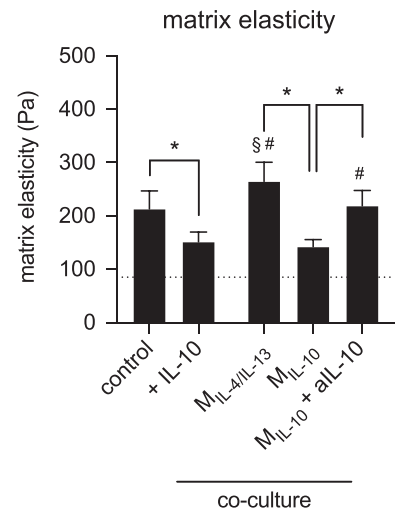

Fig. 7 Matrix remodeling by myofibroblasts in the presence of IL-10 and co-culture with M2 subtypes. a Representative images of decellularized collagen matrices in mono and co-culture with M2 subtypes (scale bar: $50 \mu \mathrm{m}$ ). Decellularized collagen matrices were characterized regarding $\mathbf{b}$ matrix porosity characterized as mean pore size, c collagen fibril diameter, and $\mathbf{d}$ matrix elastic modulus. (Data are represented as mean \pm SD; *significance level of $p \leq 0.05$ using a one-way ANOVA followed by Tukey's post hoc analysis.) The characters \# and $\S$ represent the significance level of $p \leq 0.05$ using a one-way ANOVA followed by Tukey's post hoc analysis when compared to control, and treated samples with IL-10, respectively. For the quantification of matrix porosity and collagen fibril diameter, 10 different positions of each matrix condition were analyzed. Experiments were performed in four replicates.

important for tissue repair, but not much experimental evidence exists on the migratory behavior of fibroblasts at different differentiation stages and in co-culture conditions. We performed a migration analysis of both fibroblasts and myofibroblasts in mono- and co-culture conditions to address this underlying problem. Representative side-view images of fibroblast (Fig. 8a) and myofibroblast (Fig. 8d) show that fibroblast migration into 3D collagen matrices is significantly higher than that of myofibroblasts (TGF- $\beta 1$-treated conditions), as required during early tissue repair phase. This data corroborate with our previous findings ${ }^{8,66}$. In addition, fibroblast co-culture with $\mathrm{M}_{\mathrm{IL}-10}$ exhibited a similar migration capacity in both percentage of migrating cells (Fig. 8b) and maximal migration depth (Fig. 8c) when compared to untreated fibroblasts, but exhibited significantly higher migration when compared to myofibroblast and in co-culture with $\mathrm{M}_{\mathrm{IL}-4 / \mathrm{IL}-13}$. In another experiment, modeling the late tissue repair phase, where pre-differentiated myofibroblasts were seeded onto 3D collagen matrices, we found that myofibroblasts showed limited migration into collagen matrices (Fig. 8d). However, an enhanced migration of myofibroblast in the presence of IL-10 and in coculture with $\mathrm{M}_{\mathrm{IL}-10}$ could be observed both in the migrating cell number (Fig. 8e) and maximal migration depth (Fig. 8f). Myofibroblasts co-culture with $\mathrm{M}_{\mathrm{IL}-4 / \mathrm{LL}-13}$ and $\mathrm{M}_{\mathrm{IL}-10}$ in the presence of alL-10 showed similar migration patterns as those found in myofibroblast alone.

Overall, our data suggest that myofibroblast exhibits limited migration capacity when compared to fibroblast, which is well correlated with the high expression of aSMA and the contractile phenotypes, as previously published ${ }^{8,17,79}$. The dedifferentiation of myofibroblast into fibroblast phenotypes in the presence of IL-10 and in co-culture with $\mathrm{M}_{\mathrm{LL}-10}$ could be confirmed by migratory behavior. In addition, by neutralizing IL-10 using antibody in the co-culture with $\mathrm{M}_{\mathrm{IL}-10}$, the migratory behavior remains at the level of myofibroblasts, confirming the effect of IL-10 in myofibroblast dedifferentiation.

\section{General discussion and conclusion}

To establish wound-healing models for high-throughput assessment of pathobiological changes and testing of anti-fibrotic drugs, well-defined biosystems, including cells and their cell culture substrate, are required. Although primary human cells have become a major interest in the field of regeneration, they cannot be utilized to establish a well-defined wound model due to patient-to-patient variability as well as possible lack of data regarding their underlying activation stage. To overcome these issues, we used THP-1, a human monocytic cell line widely used as an established macrophages model in many biomedical studies such as wound repair, infection models, and immuno-oncology ${ }^{80}$. Although THP-1 based M1-like macrophage models have been extensively established, few studies attempted to study M2a- and M2c-like macrophages and address their cellular functions in the context of wound repair. In this work, we utilized collagen matrices as a biomimetic wound model and comprehensively analyzed and demonstrated that surface markers and cytokines secretion profile of $\mathrm{M}_{\mathrm{IL}-4 / \mathrm{LL}-13}$ and $\mathrm{M}_{\mathrm{IL}-10}$ is akin to $\mathrm{M} 2 \mathrm{a}$ and $\mathrm{M} 2 \mathrm{C}$ macrophages derived from human PBMC, respectively ${ }^{22,28,52}$. We showed that $\mathrm{M}_{\mathrm{IL}-4 / \mathrm{LL}-13}$ can modulate tissue repair by controlled secretion of TGF- $\beta 1$ to induce fibroblast differentiation, while $\mathrm{M}_{\mathrm{IL}-10}$ macrophages secrete high amounts of IL-10 to resolve inflammation and tissue repair processes. Besides, we demonstrate that IL-10 can reverse myofibroblast into fibroblast phenotypes, as published elsewhere ${ }^{35,66}$. By neutralizing IL-10 

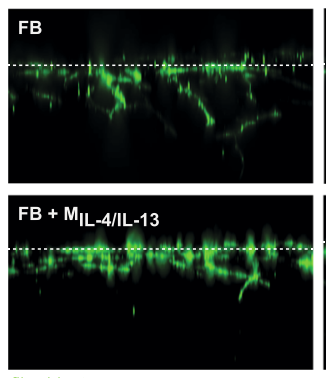

fibroblast

d
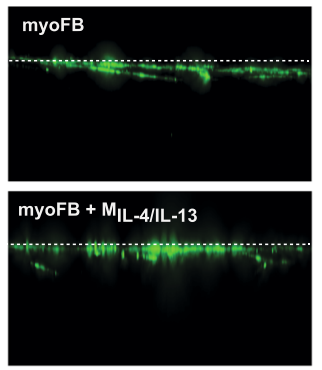

myofibroblast b
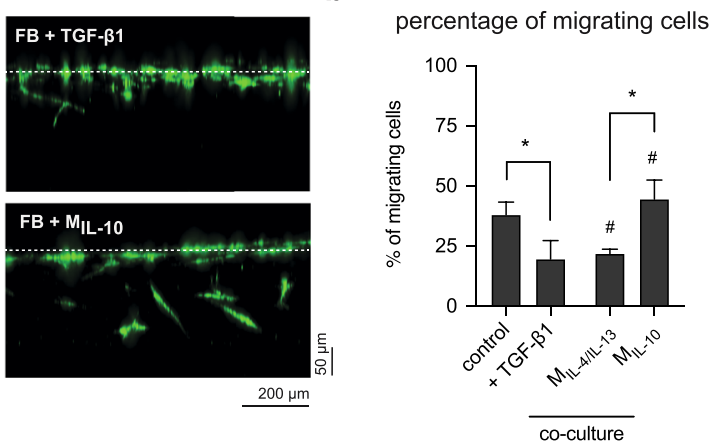

e
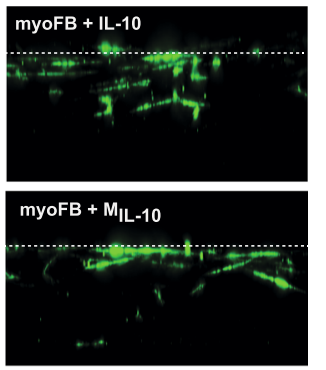

myoFB + $\mathrm{M}_{\mathrm{IL}-10}+$ alL-10

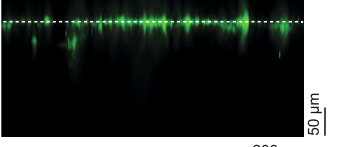

percentage of migrating cells

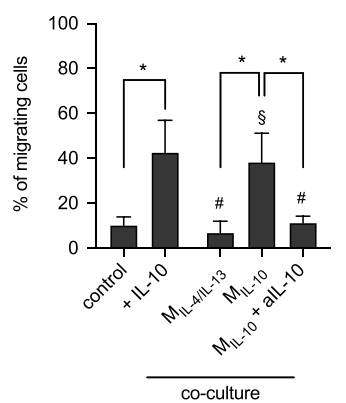

C

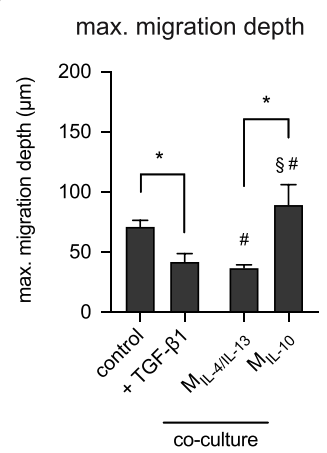

f

max. migration depth

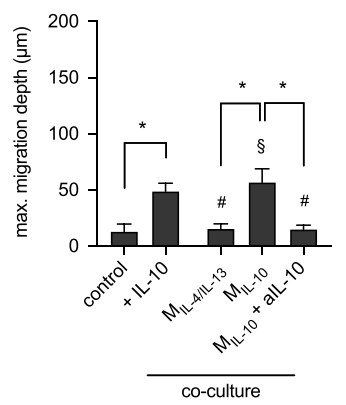

Fig. 8 Migration of fibroblasts and myofibroblasts into 3D collagen matrices. Cells were stained with Phalloidin conjugated with Alexa Fluor-488 and DAPI, for visualization and quantification of cell migration into 3D collagen matrices, respectively. Representative images of $x z-$ view of a fibroblast and $\mathbf{d}$ myofibroblast into $3 \mathrm{D}$ collagen matrices in mono- and co-culture with macrophages. Quantitative analysis of $\mathbf{b}$, $\mathbf{e}$ percentage of migrating cells and $\mathbf{c}, \mathbf{f}$ maximum migration depth of fibroblast and myofibroblasts. Cells found $>20 \mu \mathrm{m}$ beneath the matrix surface were counted as migrating cells. The maximum migration distance was defined as the distance crossed by $10 \%$ of all cells. Data are represented as mean \pm SD; *significance level of $p \leq 0.05$ using a one-way ANOVA followed by Tukey's post hoc analysis. The characters \# and $\S$ represent the significance level of $p \leq 0.05$ using a one-way ANOVA followed by Tukey's post hoc analysis when compared to control, and treated samples with TGF- $\beta 1$ or IL-10, respectively. Three different positions of each matrix condition were analyzed. Experiments were performed in four replicates.

with antibody in co-culture with $\mathrm{M}_{\mathrm{IL}-10}$, no dedifferentiation of myofibroblast could be observed, emphasizing the role of IL-10 in resolution of the tissue repair phase. An illustration summary of our results in different tissue repair phases is depicted in Fig. 9. Interestingly, we found an increase in collagen fibril diameter only in the co-culture of myofibroblasts and $\mathrm{M}_{\mathrm{IL}-4 / \mathrm{LL}-13}$ (M2a). This suggests that the contribution of $\mathrm{M}_{\mathrm{IL}-4 / \mathrm{LL}-13}$ to the tissue repair process is through remodeling provisional wound tissue ${ }^{22}$. Our recent report demonstrates that thicker collagen fibrils could activate fibroblast differentiation via cell contractility ${ }^{71}$, advancing the development of tissue scarring and fibrosis. Alongside with that, a prolonged presence of $\mathrm{M} 2 \mathrm{a}$ might also contribute to fibrosis ${ }^{81,82}$. Overall, our results pinpoint the importance of the coculture model of fibroblast and macrophages for biomimetic wound healing, instead of fibroblast monoculture. In addition, our established biomimetic model can guide the development of welldefined high-throughput platforms for improving tissue healing and anti-fibrotic drugs testing, as well as other biomedical studies.

\section{METHODS}

\section{Preparation of cell-embedded 3D collagen matrix}

To prepare collagen solution, Rat Tail type I Collagen (Advanced BioMatrix, Inc., CA, USA), $250 \mathrm{mM}$ phosphate buffer (Merck KGaA, Munich, Germany), and $0.1 \%$ acetic acid (Merck KGaA, Germany) were mixed on ice at a concentration of $2 \mathrm{mg} / \mathrm{ml}$, as previously published ${ }^{72}$. THP-1 monocytic cells
(AddexBio, CA, USA) were deposited and resuspended in the prepared collagen solution and subsequently transferred onto a glutaraldehydecoated coverslip (VWR, Darmstadt, Germany), allowing covalent binding of the collagen matrix via a lysine side chain ${ }^{18}$. The number of THP-1 cells used was $1 \times 10^{5}$ cells per 3D collagen matrix. Collagen fibrillation was initiated immediately at $37{ }^{\circ} \mathrm{C}, 5 \% \mathrm{CO}_{2}$ and $95 \%$ humidity for $45 \mathrm{~min}$. Cellembedded matrices were then rinsed three times with PBS (Merck KGaA, Germany).

\section{Cell culture and macrophages differentiation}

Cell-embedded matrices were cultured in RPMI-1640 media supplemented with $10 \%$ fetal bovine serum (FBS), $1 \%$ sodium pyruvate, $0.01 \%$ of 2 mercaptoethanol, and $1 \%$ penicillin/streptomycin at $37{ }^{\circ} \mathrm{C}, 5 \% \mathrm{CO}_{2}$, and $95 \%$ humidity. Cell culture media and supplements were purchased from Invitrogen, CA, USA.

THP-1 cells were differentiated into uncommitted macrophages using $300 \mathrm{nM}$ phorbol 12-myristate 13-acetate (PMA; Merck KGaA, Germany)) in RPMI-1640 cell culture media without FBS supplement, according to the established protocol ${ }^{18,40}$. After $6 \mathrm{~h}$, differentiation media was removed, cell-embedded matrices were washed with PBS, and rested for $24 \mathrm{~h}$ in RPMI-1640 without FBS supplement nor PMA. Afterwards, cells were activated for $48 \mathrm{~h}$ into two different macrophages subtypes $\mathrm{M} 2_{\mathrm{IL}-4 / \mathrm{L}-13}$ by treatment with $20 \mathrm{ng} / \mathrm{ml}$ interleukin 4 (IL-4; Biolegend, CA, USA) and $20 \mathrm{ng} /$ $\mathrm{ml}$ interleukin 13 (IL-13; Biolegend, USA), or into $\mathrm{M} 2_{\mathrm{IL}-10}$ by adding $20 \mathrm{ng} /$ $\mathrm{ml}$ interleukin 10 (IL-10; Biolegend, USA).

After successful cell activation, cells were imaged in a bright-field mode by a DMi8 $\mathrm{S}$ microscope using $\times 20$ long distance objective (NA 0.4; Leica, 


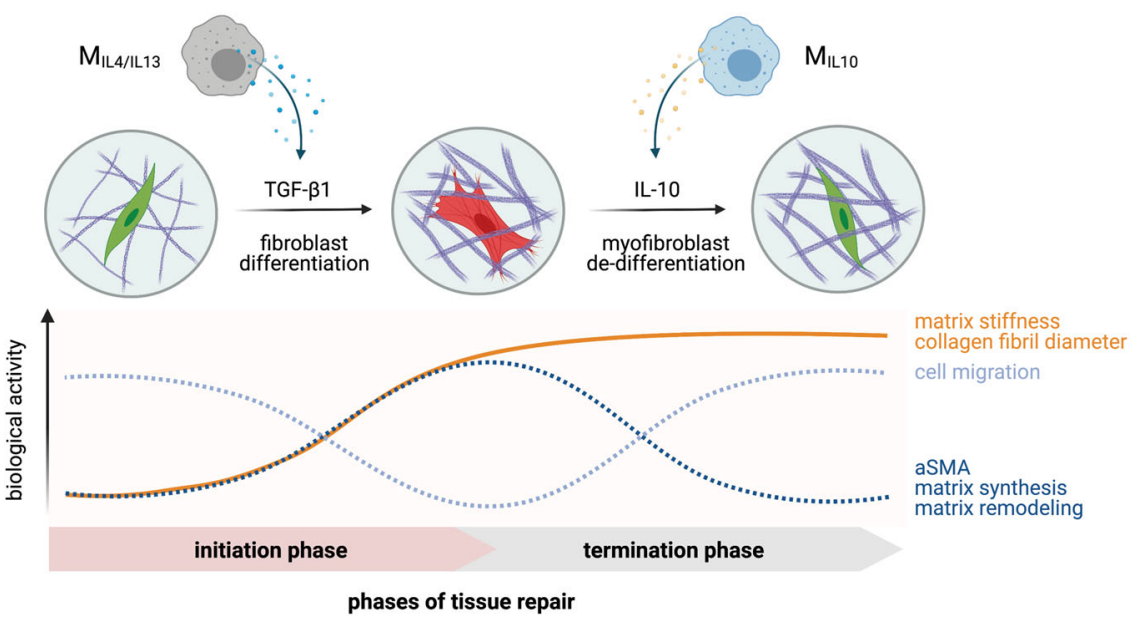

Fig. 9 Schematic illustration of the proposed M2-associated functions in initiation and termination phases of tissue repair in 3D biomimetic wound-healing model. $\mathrm{M}_{\mathrm{LL}-4 / \mathrm{LL}-13}$ macrophages control the initiation of tissue repair by modulating fibroblast differentiation via TGF- $\beta 1$, while $\mathrm{M}_{\mathrm{IL}-10}$ macrophages terminate the tissue repair by de-differentiating myofibroblasts back into fibroblasts via IL-10.

Germany). Cell area and cell aspect ratio (cell length/cell width) were analyzed using an automated image analysis toolbox ${ }^{38}$. At least 100 cells were analyzed. The experiment was performed at least in triplicates.

\section{Quantitative analysis of macrophage cell surface markers}

To study the expression of cell surface markers, cells were harvested from 3D collagen matrices by digestion with $6 \mathrm{mg} / \mathrm{ml}$ type IV collagenase (Worthington, NJ, USA) for $10 \mathrm{~min}$ at the standard cell culture conditions. Prior cell staining, cells were incubated with Human TruStain FCX ${ }^{T M}-F c$ Receptor Blocking Solution ( $5 \mu \mathrm{l}$ of blocking solution in $100 \mu \mathrm{l}$ of staining volume; Biolegend, USA) for $5 \mathrm{~min}$ at standard cell culture conditions. Cells were then stained with mouse anti-human antibodies against CD14, CD68, CD80, CD86, CD105, CD163, CD206, HLA-DR, and DRAQ7 (live/dead staining dye) for $30 \mathrm{~min}$ at standard cell culture conditions. Antibodies and DRAQ7 dye were diluted in cell culture medium at a ratio of 1:250. All antibodies used in this study were purchased from Biolegend, USA and listed with conjugated dye, clone, isotype, and catalog number in Supplementary Table 1. Stained cells were analyzed using Attune NxT Flow Cytometer equipped with an autosampler (Thermo Fisher Scientific, CA, USA). Compensation settings were applied prior to running the analysis. Data analysis was done using FlowJo software ((Becton, Dickinson and Company, NJ, USA). Gating strategy and representative histogram plot were depicted in Supplementary Fig. 2. gMFI of cell surface markers was evaluated. Experiments were performed in four replicates.

\section{Quantitative analysis of cytokine secretion profile}

To analyze cytokines secreted by macrophages, cell culture supernatants were collected after cell activation. Bead-based multiplex immunoassay for IL-4, IL-2, CXCL10 (IP-10), IL-1 $\beta$, TNF-a, MCP-1 (CCL-2), IL-17A, IL-6, IL-10, IFN- $\gamma$, IL-12p70, IL-8 (CXCL8), and TGF- $\beta 1$ (Human essential immune response panel; Biolegend, USA) was utilized to quantify cytokines following instructions by the manufacturer. Samples were analyzed using an Attune NXT Flow Cytometer equipped with autosampler (Thermo Fisher Scientific, USA). Data analysis was done by applying a five-parameter curve fitting algorithm using LEGENDplex ${ }^{\mathrm{TM}}$ data analysis software (Biolegend, USA). Experiments were performed in six replicates.

\section{Co-culture with fibroblasts and myofibroblasts}

For the co-culture with fibroblasts, macrophages activation media was removed, and matrices were washed three times with PBS prior to the introduction of fibroblasts/myofibroblasts. $1 \times 10^{4}$ human primary dermal fibroblasts (ATCC, VA, USA) were seeded onto 3D collagen matrices with and without embedded macrophages and cultured for an additional 3 days at standard cell culture conditions.

For the co-culture with myofibroblasts, human primary dermal fibroblasts (ATCC, USA) were pre-differentiated into myofibroblasts by culturing onto 2D tissue culture plate in the presence of $10 \mathrm{ng} / \mathrm{ml}$ of recombinant human TGF- $\beta 1$ (Biolegend, USA) for 3 days at standard cell culture conditions. Pre-differentiated myofibroblasts were quantified regarding their specific markers, namely aSMA, Coll1a1, and EDA-FN to ensure the differentiation (Supplementary Fig. 3). Afterwards, myofibroblasts were detached using TrypLE ${ }^{\mathrm{TM}}$ Express Enzyme (1X) with phenol red. Similar to co-culture with fibroblasts, macrophages activation media was removed, and matrices were washed three times with PBS prior to the introduction of myofibroblasts. $1 \times 10^{4}$ pre-differentiated myofibroblasts were seeded onto 3D collagen matrices with and without embedded macrophages. Co-culture of myofibroblasts and each macrophage subtype was performed for 3 days at standard cell culture conditions.

To verify the effect of IL-10 in myofibroblast dedifferentiation, we performed IL-10 blocking experiment in co-culture with $\mathrm{M} 2_{\mathrm{IL}-10}$, where $5 \mu \mathrm{g} / \mathrm{ml}$ of anti-human IL-10 antibody (alL-10; Biolegend, USA) was supplemented to the cell culture media. Cells were culture for 3 days at standard cell culture condition prior to further analyses. All co-culture experiments were performed in four replicates.

\section{Cell staining and imaging}

Cells were fixed with $4 \%$ paraformaldehyde (Biolegend, USA) for $10 \mathrm{~min}$ and permeabilized with $0.1 \%$ Triton X100 (Merck KGaA, Germany) for $10 \mathrm{~min}$. Cells were washed three times with PBS after each step. Afterwards, cells were stained with Phalloidin conjugated with Alexa Fluor 594 (dilution 1:250 in PBS; Invitrogen, Carlsbad, CA, USA) and Hoechst33342 (dilution 1:10,000 in PBS; Invitrogen, Carlsbad, CA, USA). For staining the aSMA, cells were blocked with $1 \%$ bovine serum albumin for $1 \mathrm{~h}$ at room temperature, incubated with mouse anti-human aSMA (dilution 1:250 in PBS; Biolegend, USA) overnight at $4{ }^{\circ} \mathrm{C}$, and incubated with goat anti-mouse IgG conjugated with Alexa Fluor-488 (dilution 1:250 in PBS; Invitrogen, USA) for $2 \mathrm{~h}$. Cells were washed three times with PBS after each step. Cell imaging was performed using an epi-fluorescence microscope (DMi8 S; Leica, Germany) using a $\times 20$ long distance objective (NA 0.4; Leica, Germany).

\section{Gene expression analysis}

Gene expression analysis was performed using an established protocol ${ }^{18}$. Briefly, RNA was extracted using TRIzol (Invitrogen, USA). The RNA concentration and the ratio of absorbance at 260 and $280 \mathrm{~nm}$ of cDNA were quantified using NanoDrop Spectrophotometers (Thermo Fisher Scientific, USA). Afterwards, RNA was converted into complementary DNA (cDNA) using high-capacity cDNA reverse transcription kit (Applied Biosystems, Foster City, CA, USA). The primers were synthesized from Bioneer (Republic of Korea). Quantitative polymerase chain reaction (qPCR) was performed using the SYBR Green PCR Master Mix (Applied Biosystems, USA) and was set as follows: denaturation for $5 \mathrm{~min}$ at $95^{\circ} \mathrm{C} ; 45$ cycles of denaturation $\left(95^{\circ} \mathrm{C}, 15 \mathrm{~s}\right)$, annealing under primer-specific conditions $(30 \mathrm{~s})$, and target gene-specific extension $\left(30 \mathrm{~s}\right.$ at $\left.72^{\circ} \mathrm{C}\right)$. Fluorescence signals were measured for $20 \mathrm{~s}$ at $72{ }^{\circ} \mathrm{C}$. RPS 26 gene was used as a reference gene. All primer sequences with accession number are listed in 
Supplementary Table 2. To confirm the specificity of the PCR products, melting curve analysis was performed at the end of each run. Both CDNA synthesis and qPCR were conducted using Stratagene Mx3005P (Agilent Technologies, CA, USA). The relative expression levels were calculated using the $2^{-\Delta \Delta C T}$ method. Experiments were undertaken in four replicates.

\section{Topological and mechanical characterization of 3D collagen matrix}

Cell-embedded matrices were decellularized by osmotic shock through incubation with distilled water for $1 \mathrm{~h}$, as previously published ${ }^{83}$. Afterwards, cell-free collagen matrices were analyzed to assess their topological and mechanical properties. Briefly, for topological analysis, collagen matrices were stained with $50 \mu \mathrm{M}$ of 5-(and-6)-carboxytetramethylrhodamine succinimidyl ester (TAMRA-SE, Sigma-Aldrich) and visualized by confocal laser scanning microscope (cLSM) (SP8; Leica, Germany) using $\times 40$ water immersion objective (Leica, Germany), as published elsewhere ${ }^{72}$. The CLSM stacked images were analyzed using a custom-built MATLAB script (MATLAB 2019a; MathWorks, USA) ${ }^{84}$. For the quantification of pore size and fibril diameter of collagen matrices, stacked images of 10 different positions of each matrix condition were analyzed. Mechanical properties of cell-free matrices were analyzed using nondestructive rheological measurement using ElastoSens ${ }^{\mathrm{TM}}$ Bio (Rheolution, Quebec, Canada) ${ }^{18}$. The topological and mechanical characterization were performed in four replicates.

\section{Cell migration into 3D collagen matrices}

Fibroblast migration into $3 \mathrm{D}$ collagen matrices was quantitatively determined by analyzing Hoechst-33342 fluorescence signal from individual cell nuclei, as previously reported ${ }^{72}$. Z-stack images with an interval of $5 \mu \mathrm{m}$ were gathered using an epi-fluorescence microscope with an automatic scanning stage (DMi8 S; Leica, Germany) using a $\times 10$ dry objective (Leica, Germany). For each experiment, three different positions of each cell culture condition were analyzed. The $z$-position of cell nuclei as a function of migration distance was examined using a custom-built MATLAB script (MATLAB R2019b; MathWorks Inc., USA). Since macrophages exhibit relatively less actin expression when compared to fibroblasts/myofibroblasts, we use this phenomenon to distinguish fibroblasts for migration analysis. Cells located $>20 \mu \mathrm{m}$ below the collagen matrix surface were classified and counted as migrated cells. Maximum migration distance was defined as the distance that was crossed by $10 \%$ of all migrating cells. For visualization of cell migration into 3D collagen matrices in Fig. 8, fluorescence signal of Phalloidin conjugated with Alexa Fluor-488 was used. Experiments were performed in four independent replicates.

\section{Statistical analysis}

Experiments were performed at least in four replicates unless otherwise stated. Error bars indicate standard deviation (SD). Levels of statistical significance were determined by a Mann-Whitney test or by a one-way ANOVA followed by Tukey's post hoc analysis using GraphPad Prism 8 (GraphPad Software, USA). The significance level was set at $p<0.05$.

\section{Reporting summary}

Further information on research design is available in the Nature Research Reporting Summary linked to this article.

\section{DATA AVAILABILITY}

The datasets generated during and/or analyzed during the current study are available from the corresponding author on reasonable request.

\section{CODE AVAILABILITY}

Custom script was built to measure (1) collagen microarchitecture and (2) maximum cellular migration depth into collagen hydrogels. Script 1 can be assessed here: https://git.sc.uni-leipzig.de/pe695hoje/topology-analysis and 2 can be made available upon reasonable request.
Received: 16 May 2021; Accepted: 29 October 2021; Published online: 30 November 2021

\section{REFERENCES}

1. Tottoli, E. M. et al. Skin wound healing process and new emerging technologies for skin wound care and regeneration. Pharmaceutics 12, 1-30. (2020).

2. Reinke, J. M. \& Sorg, H. Wound repair and regeneration. Eur. Surg. Res. 49, 35-43 (2012).

3. Schultz, G. S. \& Wysocki, A. Interactions between extracellular matrix and growth factors in wound healing. Wound Repair Regen. 17, 153-162 (2009).

4. Leoni, G., Neumann, P. A., Sumagin, R., Denning, T. L. \& Nusrat, A. Wound repair: role of immune-epithelial interactions. Mucosal Immunol. 8, 959-968 (2015).

5. Wilkinson, H. N. \& Hardman, M. J. Wound healing: cellular mechanisms and pathological outcomes: cellular mechanisms of wound repair. Open Biol. 10, 200223 (2020).

6. Addis, R. et al. Fibroblast proliferation and migration in wound healing by phytochemicals: evidence for a novel synergic outcome. Int. J. Med. Sci. 17, 1030-1042 (2020).

7. Clark, R. A. F. F., Lin, F., Greiling, D., An, J. \& Couchman, J. R. Fibroblast invasive migration into fibronectin/fibrin gels requires a previously uncharacterized dermatan sulfate-CD44 proteoglycan. J. Invest. Dermatol. 122, 266-277 (2004).

8. Sapudom, J. et al. The interplay of fibronectin functionalization and TGF- $\beta 1$ presence on fibroblast proliferation, differentiation and migration in 3D matrices. Biomater. Sci. 3, 1291-1301 (2015).

9. Meng, X. M., Nikolic-Paterson, D. J. \& Lan, H. Y. TGF- $\beta$ : the master regulator of fibrosis. Nat. Rev. Nephrol. 12, 325-338 (2016).

10. Clark, R. A. F., Lin, F., Greiling, D., An, J. \& Couchman, J. R. Fibroblast invasive migration into fibronectin/fibrin gels requires a previously uncharacterized dermatan sulfate-CD44 proteoglycan. J. Invest. Dermatol. 122, 266-277 (2004).

11. Lohmann, N. et al. Glycosaminoglycan-based hydrogels capture inflammatory chemokines and rescue defective wound healing in mice. Sci. Transl. Med. 9, eaai9044 (2017).

12. Koehler, L. et al. Sulfated hyaluronan derivatives modulate TGF- $\beta 1$ : receptor complex formation: possible consequences for TGF- $\beta 1$ signaling. Sci. Rep. 7, 1210 (2017).

13. Finnson, K. W., Arany, P. R. \& Philip, A. Transforming growth factor beta signaling in cutaneous wound healing: lessons learned from animal studies. Adv. Wound Care 2, 225-237 (2013).

14. Hinz, B. Formation and function of the myofibroblast during tissue repair. $J$. Invest. Dermatol. 127, 526-537 (2007).

15. Hinz, B., Celetta, G., Tomasek, J. J., Gabbiani, G. \& Chaponnier, C. Alpha-smooth muscle actin expression upregulates fibroblast contractile activity. Mol. Biol. Cell 12, 2730-2741 (2001).

16. Tomasek, J. J., Gabbiani, G., Hinz, B., Chaponnier, C. \& Brown, R. A. Myofibroblasts and mechano-regulation of connective tissue remodelling. Nat. Rev. Mol. Cell Biol. 3, 349-363 (2002).

17. Wipff, P. J., Rifkin, D. B., Meister, J. J. \& Hinz, B. Myofibroblast contraction activates latent TGF- $\beta 1$ from the extracellular matrix. J. Cell Biol. 179, 1311-1323 (2007).

18. Sapudom, J. et al. Collagen fibril density modulates macrophage activation and cellular functions during tissue repair. Bioengineering 7, 33 (2020).

19. Sohutskay, D. O., Buno, K. P., Tholpady, S. S., Nier, S. J. \& Voytik-Harbin, S. L. Design and biofabrication of dermal regeneration scaffolds: role of oligomeric collagen fibril density and architecture. Regen. Med. 15, 1295-1312 (2020).

20. Pohlers, D. et al. TGF- $\beta$ and fibrosis in different organs-molecular pathway imprints. Biochim. Biophys. Acta 1792, 746-756 (2009).

21. Darby, I. A., Zakuan, N., Billet, F. \& Desmoulière, A. The myofibroblast, a key cell in normal and pathological tissue repair. Cell. Mol. Life Sci. 73, 1145-1157 (2016).

22. Lech, M. \& Anders, H. J. Macrophages and fibrosis: how resident and infiltrating mononuclear phagocytes orchestrate all phases of tissue injury and repair. Biochim. Biophys. Acta 1832, 989-997 (2013).

23. Boniakowski, A. E., Kimball, A. S., Jacobs, B. N., Kunkel, S. L. \& Gallagher, K. A. Macrophage-mediated inflammation in normal and diabetic wound healing. J. Immunol. 199, 17-24 (2017).

24. Novak, M. L. \& Koh, T. J. Macrophage phenotypes during tissue repair. J. Leukoc. Biol. 93, 875-881 (2013).

25. Krzyszczyk P., Schloss R., Palmer A. \& Berthiaume F. The role of macrophages in acute and chronic wound healing and interventions to promote pro-wound healing phenotypes. Front. Physiol. 9, https://doi.org/10.3389/fphys.2018.00419 (2018).

26. Ploeger, D. T. et al. Cell plasticity in wound healing: paracrine factors of M1/M2 polarized macrophages influence the phenotypical state of dermal fibroblasts. Cell Commun. Signal. 11, 29 (2013). 
27. Shapouri-Moghaddam, A. et al. Macrophage plasticity, polarization, and function in health and disease. J. Cell Physiol. 233, 6425-6440 (2018).

28. Murray, P. J. et al. Macrophage activation and polarization: nomenclature and experimental guidelines. Immunity 41, 14-20 (2014).

29. Makita, N., Hizukuri, Y., Yamashiro, K., Murakawa, M. \& Hayashi, Y. IL-10 enhances the phenotype of M2 macrophages induced by IL-4 and confers the ability to increase eosinophil migration. Int. Immunol. 27, 131-141 (2015).

30. Parsa, R. et al. Adoptive transfer of immunomodulatory $M 2$ macrophages prevents type 1 diabetes in NOD mice. Diabetes 61, 2881-2892 (2012).

31. Loegl, J. et al. Hofbauer cells of $M 2 a, M 2 b$ and $M 2 c$ polarization may regulate feto-placental angiogenesis. Reproduction 152, 447-455 (2016).

32. Baker, B. M. \& Chen, C. S. Deconstructing the third dimension-how 3D culture microenvironments alter cellular cues. J. Cell Sci. 125, 3015-3024 (2012).

33. Sapudom, J. \& Pompe, T. Biomimetic tumor microenvironments based on collagen matrices. Biomater. Sci. 6, 2009-2024 (2018).

34. Court, M., Malier, M. \& Millet, A. 3D type I collagen environment leads up to a reassessment of the classification of human macrophage polarizations. Biomaterials 208, 98-109 (2019).

35. Ullm, F. et al. 3D scaffold-based macrophage fibroblast coculture model reveals IL-10 dependence of wound resolution phase. Adv. Biosyst. 4, 1900220 (2020).

36. Smithmyer, M. E., Sawicki, L. A. \& Kloxin, A. M. Hydrogel scaffolds as in vitro models to study fibroblast activation in wound healing and disease. Biomater. Sci. 2, 634-650 (2014)

37. Sapudom, J., Rubner, S., Martin, S. \& Pompe, T. Mimicking tissue boundaries by sharp multiparameter matrix interfaces. Adv. Health. Mater. 5, 1861-1867 (2016).

38. Sapudom, J., Waschke, J., Franke, K., Hlawitschka, M. \& Pompe, T. Quantitative label-free single cell tracking in 3D biomimetic matrices. Sci. Rep. 7, 14135 (2017).

39. Stöger, J. L. et al. Distribution of macrophage polarization markers in human atherosclerosis. Atherosclerosis 225, 461-468 (2012).

40. Garcia-Sabaté, A. et al. Biomimetic 3D models for investigating the role of monocytes and macrophages in atherosclerosis. Bioengineering 7, 1-20. (2020).

41. Wang, Lxun, Zhang, Sxi, Wu, Hjuan, Rong, Xlu \& Guo, J. M2b macrophage polarization and its roles in diseases. J. Leukoc. Biol. 106, 345-358 (2019).

42. Lee, J. et al. The MHC class II antigen presentation pathway in human monocytes differs by subset and is regulated by cytokines. PLOS ONE 12, e0183594 (2017).

43. Sandanger, $\varnothing$. et al. IL-10 enhances MD-2 and CD14 expression in monocytes and the proteins are increased and correlated in HIV-infected patients. J. Immunol. 182, 588-595 (2009).

44. Parker, D. CD80/CD86 signaling contributes to the proinflammatory response of Staphylococcus aureus in the airway. Cytokine 107, 130-136 (2018).

45. Raggi, F. et al. Regulation of human macrophage M1-M2 polarization balance by hypoxia and the triggering receptor expressed on myeloid cells-1. Front. Immunol. 8, https://doi.org/10.3389/fimmu.2017.01097 (2017).

46. Okeke E. B. \& Uzonna J. E. The pivotal role of regulatory T cells in the regulation of innate immune cells. Front. Immunol. 10, https://doi.org/10.3389/ fimmu.2019.00680 (2019).

47. Romano, M., Fanelli, G., Albany, C. J., Giganti, G. \& Lombardi, G. Past, present, and future of regulatory $\mathrm{T}$ cell therapy in transplantation and autoimmunity. Front. Immunol. 10, https://doi.org/10.3389/fimmu.2019.00043 (2019).

48. Yu, X., Guo, C., Fisher, P. B., Subjeck, J. R. \& Wang, X. Y. Scavenger receptors: emerging roles in cancer biology and immunology. Adv. Cancer Res. 128, 309-364 (2015).

49. Iqbal, S. \& Kumar, A. Characterization of in vitro generated human polarized macrophages. J. Clin. Cell Immunol. 6, https://doi.org/10.4172/2155-9899.1000380 (2015).

50. Etzerodt, A. \& Moestrup, S. K. CD163 and inflammation: biological, diagnostic, and therapeutic aspects. Antioxid. Redox Signal. 18, 2352-2363 (2013).

51. Eming, S. A., Krieg, T. \& Davidson, J. M. Inflammation in wound repair: molecular and cellular mechanisms. J. Invest. Dermatol. 127, 514-525 (2007).

52. Xue, J. et al. Transcriptome-based network analysis reveals a spectrum model of human macrophage activation. Immunity 40, 274-288 (2014).

53. Kanno, E. et al. Defect of interferon $\gamma$ leads to impaired wound healing through prolonged neutrophilic inflammatory response and enhanced MMP-2 activation. Int. J. Mol. Sci. 20, 5657 (2019).

54. Li, J. et al. Effect of recombinant interleukin-12 on murine skin regeneration and cell dynamics using in vivo multimodal microscopy. Biomed. Opt. Express 6, 4277 (2015).

55. Ding, J. \& Tredget, E. E. The role of chemokines in fibrotic wound healing. Adv. Wound Care 4, 673-686 (2015).

56. Park, M. J. et al. IL-1-IL-17 signaling axis contributes to fibrosis and inflammation in two different murine models of systemic sclerosis. Front. Immunol. 9, https:// doi.org/10.3389/fimmu.2018.01611 (2018)

57. Johnson, B. Z., Stevenson, A. W., Prêle, C. M., Fear, M. W. \& Wood, F. M. The role of IL-6 in skin fibrosis and cutaneous wound healing. Biomedicines 8, 101 (2020).

58. Yang, Y. M. \& Seki, E. TNFa in liver fibrosis. Curr. Pathobiol. Rep. 3, 253-261 (2015).
59. Gong, D. et al. TGF $\beta$ signaling plays a critical role in promoting alternative macrophage activation. BMC Immunol. 13, 31 (2012).

60. Shen, J. et al. IL-17 induces macrophages to M2-like phenotype via NF-KB. Cancer Manag Res. 10, 4217-4228 (2018).

61. Takagi, N. et al. IL-17A promotes neutrophilic inflammation and disturbs acute wound healing in skin. Exp. Dermatol. 26, 137-144 (2017).

62. Zizzo, G. \& Cohen, P. L. IL-17 stimulates differentiation of human antiinflammatory macrophages and phagocytosis of apoptotic neutrophils in response to IL-10 and glucocorticoids. J. Immunol. 190, 5237-5246 (2013).

63. Sato, Y., Ohshima, T. \& Kondo, T. Regulatory role of endogenous interleukin-10 in cutaneous inflammatory response of murine wound healing. Biochem. Biophys. Res. Commun. 265, 194-199 (1999).

64. Peranteau, W. H. et al. IL-10 overexpression decreases inflammatory mediators and promotes regenerative healing in an adult model of scar formation. J. Invest. Dermatol. 128, 1852-1860 (2008).

65. King, A., Balaji, S., Le, L. D., Crombleholme, T. M. \& Keswani, S. G. Regenerative wound healing: the role of interleukin-10. Adv. Wound Care 3, 315-323 (2014).

66. Sapudom, J. et al. Fibroblast fate regulation by time dependent TGF- $\beta 1$ and IL-10 stimulation in biomimetic 3D matrices. Biomater. Sci. 5, 1858-1867 (2017).

67. LEASK, A. TGF- signaling and the fibrotic response. FASEB J. 18, 816-827 (2004).

68. Hinz, B. et al. The myofibroblast. Am. J. Pathol. 170, 1807-1816 (2007).

69. Ansorge, M. et al. Short-range cytokine gradients to mimic paracrine cell interactions in vitro. J. Control Release 224, 59-68 (2016).

70. Wilgus, T. A. Inflammation as an orchestrator of cutaneous scar formation: a review of the literature. Plast. Aesthetic Res. 2020, https://doi.org/10.20517/23479264.2020 .150 (2020).

71. Seo, B. R. et al. Collagen microarchitecture mechanically controls myofibroblast differentiation. Proc. Natl Acad. Sci. USA 117, 201919394 (2020).

72. Sapudom, J. et al. The phenotype of cancer cell invasion controlled by fibril diameter and pore size of 3D collagen networks. Biomaterials 52, 367-375 (2015).

73. Sapudom, J. et al. Fibril bending stiffness of 3D collagen matrices instructs spreading and clustering of invasive and non-invasive breast cancer cells. Biomaterials 193, 47-57 (2019).

74. Doyle, A. D., Carvajal, N., Jin, A., Matsumoto, K. \& Yamada, K. M. Local 3D matrix microenvironment regulates cell migration through spatiotemporal dynamics of contractility-dependent adhesions. Nat. Commun. 6, 8720 (2015).

75. Hinz, B. \& Lagares, D. Evasion of apoptosis by myofibroblasts: a hallmark of fibrotic diseases. Nat. Rev. Rheumatol. 16, 11-31 (2020).

76. Balaji, S. et al. Interleukin-10-mediated regenerative postnatal tissue repair is dependent on regulation of hyaluronan metabolism via fibroblast-specific STAT3 signaling. FASEB J. 31, 868-881 (2017).

77. Borthwick, L. A., Wynn, T. A. \& Fisher, A. J. Cytokine mediated tissue fibrosis. Biochim Biophys. Acta 1832, 1049-1060 (2013).

78. Distler, J. H. W. et al. Shared and distinct mechanisms of fibrosis. Nat. Rev. Rheumatol. 15, 705-730 (2019).

79. Rønnov-Jessen, L. \& Petersen, O. W. A function for filamentous alpha-smooth muscle actin: retardation of motility in fibroblasts. J. Cell Biol. 134, 67-80 (1996).

80. Auwerx, J. The human leukemia cell line, THP-1: a multifacetted model for the study of monocyte-macrophage differentiation. Experientia 47, 22-31 (1991).

81. Feng, Y. et al. Direct and indirect roles of macrophages in hypertrophic scar formation. Front. Physiol. 10, https://doi.org/10.3389/fphys.2019.01101 (2019).

82. $\mathrm{Xu}, \mathrm{X}$. et al. The role of macrophages in the formation of hypertrophic scars and keloids. Burn Trauma 8, https://doi.org/10.1093/burnst/tkaa006 (2020).

83. Sapudom, J. et al. Biomimetic tissue models reveal the role of hyaluronan in melanoma proliferation and invasion. Biomater. Sci. 8, 1405-1417 (2020).

84. Franke, K., Sapudom, J., Kalbitzer, L., Anderegg, U. \& Pompe, T. Topologically defined composites of collagen types I and V as in vitro cell culture scaffolds. Acta Biomater. 10, 2693-2702 (2014).

\section{ACKNOWLEDGEMENTS}

The authors acknowledge the support from New York University Abu Dhabi (NYUAD) Faculty Research Fund (AD266). The authors would also like to acknowledge support from NYUAD core technology platform. Experiments were performed using the NYUAD Light Microscopy and Molecular and Cell Biology Platforms.

\section{AUTHOR CONTRIBUTIONS}

J.S. and J.C.M.T. devised the project and the main conceptual ideas. J.S., S.K., W.K.E.M., and B.C.Q. performed the experiments. J.S., S.K., and A.G.-S. analyzed experimental data. J.S. took the lead in writing the manuscript with input from the authors. All authors provided critical feedback and helped shape the research, analysis, and manuscript. J.C.M.T. supervised the project. 


\section{COMPETING INTERESTS}

The authors declare no competing interests.

\section{ADDITIONAL INFORMATION}

Supplementary information The online version contains supplementary material available at https://doi.org/10.1038/s41536-021-00193-5.

Correspondence and requests for materials should be addressed to Jeremy C. M. Teo

Reprints and permission information is available at http://www.nature.com/reprints

Publisher's note Springer Nature remains neutral with regard to jurisdictional claims in published maps and institutional affiliations.
Open Access This article is licensed under a Creative Commons Attribution 4.0 International License, which permits use, sharing, adaptation, distribution and reproduction in any medium or format, as long as you give appropriate credit to the original author(s) and the source, provide a link to the Creative Commons license, and indicate if changes were made. The images or other third party material in this article are included in the article's Creative Commons license, unless indicated otherwise in a credit line to the material. If material is not included in the article's Creative Commons license and your intended use is not permitted by statutory regulation or exceeds the permitted use, you will need to obtain permission directly from the copyright holder. To view a copy of this license, visit http://creativecommons. org/licenses/by/4.0/.

(c) The Author(s) 2021 